\title{
RESEARCH
}

Open Access

\section{Nicotinamide inhibits melanoma in vitro and in vivo}

\author{
Francesca Scatozza ${ }^{1 \dagger}$, Federica Moschella ${ }^{2 \dagger}$, Daniela D'Arcangelo ${ }^{1 \dagger}$, Stefania Rossi ${ }^{2}$, Claudio Tabolacci ${ }^{2}$, \\ Claudia Giampietri ${ }^{3}$, Enrico Proietti ${ }^{2}$, Francesco Facchiano ${ }^{2^{*}}$ and Antonio Facchiano ${ }^{1^{*}}$ (D)
}

\begin{abstract}
Background: Even though new therapies are available against melanoma, novel approaches are needed to overcome resistance and high-toxicity issues. In the present study the anti-melanoma activity of Nicotinamide (NAM), the amide form of Niacin, was assessed in vitro and in vivo.
\end{abstract}

Methods: Human (A375, SK-MEL-28) and mouse (B16-F10) melanoma cell lines were used for in vitro investigations. Viability, cell-death, cell-cycle distribution, apoptosis, Nicotinamide Adenine Dinucleotide ${ }^{+}\left(\mathrm{NAD}^{+}\right)$, Adenosine Triphosphate (ATP), and Reactive Oxygen Species (ROS) levels were measured after NAM treatment. NAM anti-SIRT2 activity was tested in vitro; SIRT2 expression level was investigated by in silico transcriptomic analyses. Melanoma growth in vivo was measured in thirty-five C57BL/6 mice injected subcutaneously with B16-F10 melanoma cells and treated intraperitoneally with NAM. Interferon (IFN)- $\gamma$-secreting murine cells were counted with ELISPOT assay. Cytokine/chemokine plasmatic levels were measured by XMAP technology. Niacin receptors expression in human melanoma samples was also investigated by in silico transcriptomic analyses.

Results: NAM reduced up to 90\% melanoma cell number and induced: i) accumulation in G1-phase (40\% increase), ii) reduction in S- and G2-phase (about 50\% decrease), iii) a 10-fold increase of cell-death and 2.5-fold increase of apoptosis in sub-G1 phase, iv) a significant increase of NAD ${ }^{+}$, ATP, and ROS levels, v) a strong inhibition of SIRT2 activity in vitro. NAM significantly delayed tumor growth in vivo $(p \leq 0.0005)$ and improved survival of melanomabearing mice $(p \leq 0.0001)$. About 3 -fold increase $(p \leq 0.05)$ of Interferon-gamma (IFN- $\gamma)$ producing cells was observed in NAM treated mice. The plasmatic expression levels of 6 cytokines (namely: Interleukin 5 (IL-5), Eotaxin, Interleukin 12 (p40) (IL12(p40)), Interleukin 3 (IL-3), Interleukin 10 (IL-10) and Regulated on Activation Normal T Expressed and Secreted (RANTES) were significantly changed in the blood of NAM treated mice, suggesting a key role of the immune response. The observed inhibitory effect of NAM on SIRT2 enzymatic activity confirmed previous evidence; we show here that SIRT2 expression is significantly increased in melanoma and inversely related to melanoma-patients survival. Finally, we show for the first time that the expression levels of Niacin receptors HCAR2 and HCAR3 is almost abolished in human melanoma samples.

(Continued on next page)

\footnotetext{
* Correspondence: francesco.facchiano@iss.it; a.facchiano@idi.it

${ }^{\dagger}$ Francesca Scatozza, Federica Moschella and Daniela D'Arcangelo contributed equally to this work.

${ }^{2}$ Department of Oncology and Molecular Medicine, Istituto Superiore di

Sanità, Rome 00161, Italy

${ }^{1}$ IDI-IRCCS, Istituto Dermopatico dell'Immacolata, Rome 00167, Italy

Full list of author information is available at the end of the article
}

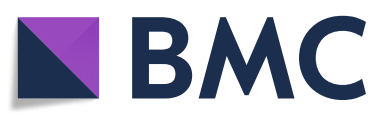

(c) The Author(s). 2020 Open Access This article is licensed under a Creative Commons Attribution 4.0 International License, which permits use, sharing, adaptation, distribution and reproduction in any medium or format, as long as you give appropriate credit to the original author(s) and the source, provide a link to the Creative Commons licence, and indicate if changes were made. The images or other third party material in this article are included in the article's Creative Commons licence, unless indicated otherwise in a credit line to the material. If material is not included in the article's Creative Commons licence and your intended use is not permitted by statutory regulation or exceeds the permitted use, you will need to obtain permission directly from the copyright holder. To view a copy of this licence, visit http://creativecommons.org/licenses/by/4.0/. The Creative Commons Public Domain Dedication waiver (http://creativecommons.org/publicdomain/zero/1.0/) applies to the data made available in this article, unless otherwise stated in a credit line to the data. 
(Continued from previous page)

Conclusion: NAM shows a relevant anti-melanoma activity in vitro and in vivo and is a suitable candidate for further clinical investigations.

Keywords: Melanoma, Nicotinamide, Vitamin B3, Melanoma mouse-animal model, Metabolism, Sirtuin 2, HCAR2, HCAR3, Dietary intake

\section{Background}

Nicotinamide (NAM) is the amide form of niacin (vitamin B3 or vitamin PP). It is a precursor of nicotinamideadenine dinucleotide $\mathrm{NAD}^{+}[1]$ and is known to play an essential role in energy metabolism and to act in several tissues including skin [2], nervous system [3, 4], and muscles [5]. Its metabolic pathway is related to tryptophan metabolism [6]. NAM is a key player in the nervous system as well as in skin physiology and immune response control [7, 8]. A severe reduction of NAM levels leads to serious pathologic conditions such as pellagra, characterized by the 3Ds symptoms, namely: Dementia, Diarrhea, and Dermatitis. If untreated, pellagra may be fatal. NAM has been recently suggested as a possible candidate to treat preeclampsia and to improve fetal growth [9]; it was shown to reduce transepidermal water loss [10] and is currently recommended to reduce the incidence of non-melanoma skin cancers in high risk individuals $[11,12]$. NAM is used to treat acne vulgaris, melasma, atopic dermatitis, and rosacea [13, 14]. The possible side effects and consequences of excessive NAM intake include increased risk of diabetes, Parkinson's disease, and liver damage [14]; nevertheless, NAM is generally considered a drug with a safe toxicity profile at daily doses of up to $3 \mathrm{~g}$. The role played by NAM and vitamin B3 in cancer control and cancer metabolism is currently under intense investigation [15-17] and several clinical trials assessing their effects in human cancers are ongoing [18]. NAM anticancer action is likely related to the ability to improve repair of the UV-induced DNA damage and to the key role in cellular energy metabolism [19]. Its chemo-preventive role in non-melanoma skin cancer is well known $[20,21]$ and is related, at least in part, to a direct anti-inflammatory activity [22]. At the present time, a role of NAM in melanoma treatment or prevention has been proposed but not demonstrated [22, 23]. Itzhaki and collaborators [24] showed that NAM inhibits vasculogenic mimicry, an alternative vascularization pathway observed in highly aggressive melanoma, by using ex vivo derived 3D primary melanoma cell cultures, and showed in vitro effects of NAM on proliferation, invasion, and cell cycle profile of melanoma cells. An additional study showed effects on melanoma cell migration and metastasis in B16-F1 cells both in vitro and in vivo models, but no impact was reported on the tumor growth rate in transplanted mice at the doses analyzed [25]. NAM intracellular levels are controlled by Sirtuins, a highly conserved family of class III deacetylase proteins. Sirtuins catalyze a reaction where $\mathrm{NAD}^{+}$is used to remove an acetyl group from a lysine residue and release NAM and acetyl-ribose as end products. Additional studies have shown the antimelanoma action of sirtuins inhibitors, [25-27], indicating that inhibiting sirtuins may represent an effective way to control melanoma growth [28]. As recently pointed out, the role played by NAM in melanoma needs further investigation [29]. NAM is a central player in controlling energy metabolism. It is a $\mathrm{NAD}^{+}$precursor; its effects have been investigated in energy and Reactive Oxygen Species (ROS) production [30], as well as in inflammation control [31, 32]. Given its central role in controlling energy production and the activity of many enzymes, NAM has been proposed in the treatment of several clinical conditions, including chemoprevention of non-melanoma skin cancer $[12,21,33]$ and chemoprevention of lung cancer [34]. We have recently identified novel molecules showing anti-melanoma activity and characterized their mechanism of action [35-39]. In the present study, we aimed at investigating NAM antitumor mechanisms of action and addressed its effects in melanoma models both in vitro and in vivo. In melanoma cells, we show that NAM induces a significant increase of $\mathrm{NAD}^{+}$, ATP, and ROS levels, a strong effect on cell cycle phases distribution, and a significant antimelanoma effect both in vitro and in vivo.

\section{Materials and methods \\ Cell culture}

Human melanoma cell lines SK-MEL-28 and A375 were purchased from the American Type Culture Collection (ATCC, Manassas, VA). SK-MEL-28 and A375 were grown respectively in Minimum Essential medium Eagle (MEM; Hyclone, South Logan, UT, USA) and Dulbecco's modified Eagle's medium (DMEM; Hyclone) supplemented with $10 \%$ fetal bovine serum (FBS; Hyclone), 2 $\mathrm{mML}$-glutamine, and $100 \mathrm{mM}$ penicillin/streptomycin (Invitrogen, Carlsbad, CA, USA), as previously reported [38]. B16-F10 mouse melanoma cells from ATCC were grown in DMEM containing 10\% FBS (Hyclone), $2 \mathrm{mM}$ L-glutamine and $100 \mathrm{mM}$ penicillin/streptomycin (Invitrogen), at $37^{\circ} \mathrm{C}$ with $5 \% \mathrm{CO}_{2}$. 


\section{Cell proliferation}

NAM effect on cell number was measured by cell counting. SK-MEL-28 were plated at $1 \times 10^{5}$ cell/plate and A375 and B16-F10 cells were plated at $8 \times 10^{4}$ cell/plate in p35 Petri dishes at time 0. Cells were then starved for $18 \mathrm{~h}$ in serum-free medium and the next day treated with NAM 1, 20, and $50 \mathrm{mM}$ in complete fresh medium containing FBS 10\%. Cells were then harvested with $0.25 \%$ trypsin, $2.21 \mathrm{mM}$ EDTA, $1 \mathrm{x}$ sodium bicarbonate (Corning, Manassas, VA, USA) and counted at different times (24 and $48 \mathrm{~h}$ ). NAM was from DSM Nutritional products Ltd. (CH-4002 Basel, Switzerland) (Niacinamide PC, code 5006066). Trypan blue exclusion was used to discriminate live from dead cells.

\section{Cell-cycle investigation by FACS analysis}

A375 cells were plated at $8 \times 10^{4}$ cell/plate in p35 Petri dishes at time 0 and then were starved for $18 \mathrm{~h}$ in serum-free medium. The next day, cells treated with NAM (10, 20 and $50 \mathrm{mM})$ in complete fresh medium for $24 \mathrm{~h}$ were harvested by $0.25 \%$ trypsin incubation, washed with cold phosphate-buffered saline (PBS) and fixed in $70 \%$ ethanol. Cells were then incubated with $1 \mu \mathrm{g} / \mathrm{ml}$ propidium iodide (Sigma) for $3 \mathrm{~h}$ at room temperature and then examined by using a BD Accuri C6 Plus Flow Cytometer (BD Biosciences, USA). Data were analyzed by FlowJo software by BD Biosciences.

\section{Evaluation of energy-related metabolism}

The total soluble $\mathrm{NAD}^{+}$level was measured using the $\mathrm{NAD}^{+} / \mathrm{NADH}$ assay kit based on the enzymatic cycling reaction (BioVision, Milpitas, California). SK-MEL-28 were plated at $1 \times 10^{5}$ cells/plate and A375 and B16-F10 cells were plated at $8 \times 10^{4}$ cell/plate in p35 Petri dishes at time 0 and then starved for $18 \mathrm{~h}$ in serum-free medium. After $6 \mathrm{~h}$ NAM treatment $(1,20$, and $50 \mathrm{mM})$ in the presence of $10 \% \mathrm{FBS}$, cells were washed with PBS, harvested with $0.25 \%$ trypsin and counted. According to the manufacturer's instructions, the cell lysate absorbance was measured at $450 \mathrm{~nm}$ after $6 \mathrm{~h}$ and $\mathrm{NAD}^{+}$concentration was expressed in $\mathrm{pmol} / \mu \mathrm{l}$. Intracellular ATP content was measured by using the ATP Colorimetric/ Fluorometric Assay Kit (BioVision). SK-MEL-28 and A375 cells were treated with NAM $(1,20$, and $50 \mathrm{mM})$ for $6 \mathrm{~h}$. Cells were then washed with PBS, harvested and ATP was measured following the manufacturer instructions upon cell lysis. This assay reports the ATP concentration expressed as $\mathrm{nmol} / 10^{6}$ cells.

ROS level was measured using the $2^{\prime}, 7^{\prime}$-dichlorodihydrofluorescein diacetate (DCFDA)-Cellular Reactive Oxygen Species (ROS) Detection Assay Kit (AbCam ab 113,851). Cells were incubated with $25 \mu \mathrm{M}$ DCFDA for $45 \mathrm{~min}$ at $37^{\circ} \mathrm{C}$ and then treated with $50 \mathrm{mM}$ NAM in complete fresh medium for $6 \mathrm{~h}$. Tert-Butyl Hydrogen
Peroxide (TBHP) solution was used as a positive control for ROS production. The fluorescence intensity of control and treated wells was measured with the Ensight instrument (Perkin Elmer, Inc. Beaconsfield UK) at Ex = $485 \mathrm{~nm}$ and $\mathrm{Em}=535 \mathrm{~nm}$, according to the manufacturer's instructions.

\section{SIRT2 activity assay in vitro}

NAM (from $0.01 \mathrm{mM}$ up to $20 \mathrm{mM}$ ) was used to test the effect on SIRT2 activity by using the Sirt2 Inhibitor Screening Assay Kit (Fluorometric) (BioVision). Five $\mu \mathrm{l}$ of purified SIRT2 enzyme was added to each well and then incubated with $45 \mu \mathrm{l}$ of NAM increasing concentrations and incubated for $5 \mathrm{~min}$ at $37^{\circ} \mathrm{C}$. Forty $\mu$ l of the substrate solution was then added to each well, mixed, and incubated for $60 \mathrm{~min}$ at $37^{\circ} \mathrm{C}$. The fluorescence intensity of each sample was measured before (R0) and after (R1) Developer addition, according to the manufacturer's instructions. The Ensight instrument (Perkin Elmer, Inc.) was used, at $\mathrm{Ex}=395 \mathrm{~nm}$ and $\mathrm{Em}=541 \mathrm{~nm}$. Doses expressed in $\mathrm{mM}$ concentration were logtransformed; data were then fitted with the non-linear regression equation and the $\mathrm{EC}$ value was calculated by GraphPad Prism 5 (GraphPad Software Inc.).

\section{Sirtuins transcriptomic analyses and survival analysis}

SIRT2 expression levels were investigated in NCI-60 cancer cell lines, a collection of 60 human cell lines from 9 cancer types, reported in the expression array GDS1761 within the GEO database [40]. SIRT2 expression levels in human specimens were from 211 normal skin individuals (controls) and 148 melanoma patients. More in detail, expression values were taken from GENT2 database available at http://gent2.appex. $\mathrm{kr} /$ gent2/ [41]. Normal skin data were from 10 datasets, namely: GSE13355, GSE14905, GSE15605, GSE16161, GSE30355, GSE39612, GSE42109, GSE46239, GSE7307, GSE7553); metastatic melanoma data were from 3 experiments, namely GSE77553, GSE19234, GSE22968.

Expression levels of SIRT2 in melanoma and vs control normal skin were also obtained taken from "PanCancer Analysis of Whole Genomes" reported by the Expression Atlas at EBI [42].

Survival analysis in melanoma patients was related to SIRT1, SIRT2, SIRT3, SIRT4, SIRT5, SIRT6, and SIRT7 expression levels reported by GEPIA2 database [43] available at http://gepia2.cancer-pku.cn/\#survival. Survival analyses were carried out on quartile distribution with the cutoff for high expression set at $70 \%$ and the cutoff for low expression set at 25\%, using the skin cancer melanoma (SKCM) database. 


\section{Mouse melanoma model in vivo}

The metastatic cell model B16-F10 was used as in vivo model of melanoma. Cells were expanded for a few passages and aliquots were frozen in liquid nitrogen. From each aliquot of parental stock, a second batch of aliquoted and frozen cells was generated. They were thawed before the tumor was implanted. Cells were routinely examined for Mycoplasma contamination. Thirtyfive 8-week-old C57BL/6 mice were obtained from Charles River Laboratories (Calco, Italy). Mice were housed in a pathogen-free facility of the Istituto Superiore di Sanità (Rome, Italy) under light- and temperature-controlled conditions and treated in accordance with the European Community guidelines. Experiments were approved by the ISS Review Board (Protocol number 986/SSA/13). Tumors were obtained by subcutaneous (s.c.) injection of $3 \times 10^{5}$ B16-F10 cells. NAM was freshly dissolved in saline solution and administered at $1000-1500-1800 \mathrm{mg} / \mathrm{Kg}$ doses by daily intraperitoneal (i.p.) injection either with a 5 days per week or a 7 days per week schedule. Control mice received the i.p. injection of saline solution.

Tumor growth was monitored twice a week by measuring the size of the tumor with a digital caliper reported as mean tumor diameter. Toxicity was evaluated by mice examination and body weight assessment. Mice survival was analyzed by the Kaplan-Meier method, using as endpoint the day when the tumors reached a mean diameter of $12 \mathrm{~mm}$ or the day of euthanasia. Mice were sacrificed if the tumor was necrotic, if the tumor diameter exceeded $16 \mathrm{~mm}$ or if the mice showed any sign of distress or weight loss.

\section{Interferon-gamma ELISPOT}

Fourteen days following tumor injection into C57BL/6 mice, blood samples were collected from the retroorbital plexus from individual mice in K3EDTA anticoagulant-coated tubes (MINIPLAST, LP Italiana SPA). Plasma was separated from cell fractions by lowspeed centrifugation and stored at $-80^{\circ} \mathrm{C}$ for cytokine expression analysis (see below).

A cytokine enzyme-linked immunospot (ELISPOT) assay designed for measuring the number of interferon (IFN)- $\gamma$-secreting cells in PBMCs in response to specific irradiated (20 Gy) B16-F10 tumor cells was performed. Briefly, nitrocellulose-bottomed 96-well plates (MultiScreenTM-IP, Millipore, Bedford, MA) were coated with anti-mouse IFN- $\gamma$ capture monoclonal antibody (mAb) (Mabtech, Nacka, Sweden), blood leukocytes $\left(1 \times 10^{5}\right)$ were incubated with or without $2 \times 10^{5}$ irradiated tumor cells in triplicate wells. Positive control included incubation of cells with Concanavalin A (Sigma Aldrich, USA). After $24 \mathrm{~h}$ at $37^{\circ} \mathrm{C}$, the plate was washed and then incubated with biotinylated anti-mouse IFN- $\gamma$ mAb
(Mabtech), streptavidin Alkaline Phosphatase (ALP) (Mabtech), and ALP-substrate (BCIP/NBT) (Sigma-Aldrich) according to manufacturer's instructions. The reaction was terminated by washing with tap water upon the appearance of dark spots which were then counted using the 4-Plate Elispot Reader V2.1 (A.EL.VIS, Hannover, Germany).

\section{Cytokines expression in mice plasma}

Fourteen days after tumor injection, plasma samples were obtained by individual mice and stored at $-80^{\circ} \mathrm{C}$. Conditioned media from treated cells were collected, centrifuged and stored at $-80^{\circ} \mathrm{C}$ until use. Cytokines levels were measured through xMAP multiplex technology by a Mouse Magnetic Bio-Plex assay (23-plex panel, cod. \#M60009RDPD, Bio-Rad Laboratories, Hercules, CA) including the following molecules: Interleukin (IL)$1 \alpha$, IL-1 $\beta$, IL-2, IL-3, IL-4, IL-5, IL-6, IL-9, IL-10, IL12(p70), IL-12(p40), IL-13, IL-17A, tumor necrosis factor (TNF)- $\alpha$, IFN- $\gamma$, Macrophage Inflammatory Protein (MIP)-1 $\alpha$, MIP-1 $\beta$, Eotaxin, Monocyte Chemoattractant (MCP)-1/(CCL2), Granulocyte Colony stimulating factor (G-CSF), Granulocyte Monocyte Colony Stimulating factor GM-CSF, Regulated on Activation-Normal $\mathrm{T}$ cell Expressed and Secreted (RANTES or CCL5), and KC. The analysis was carried out using $15 \mu \mathrm{l}$ of plasma samples or conditioned media diluted according to the manufacturer's instructions. Quantification was carried out on a Bio-Plex 200 System (Bio-Rad) equipped with a magnetic workstation and a Bio-Plex Manager Software version 6.1. Results were expressed as $\mathrm{pg} / \mathrm{ml}$ as previously reported [37].

\section{Analysis of niacin receptors expression}

Niacin receptors HACR1, HCAR2 and HCAR3 were investigated analyzing expression data available from two public databases, namely GEPIA2 database [43] and GEO database [44]. The dimensionality reduction tool available on GEPIA2, at http://gepia2.cancer-pku.cn/\#dimension, was exploited to perform the Principal Component Analysis (PCA) to show the genetic distance of melanoma to healthy controls according to the principal variance components of these three receptors. HCAR3 expression was also investigated on the GEO database [44] in two datasets investigating expression in normal skin vs melanoma samples (GDS1375, [45]) and in primary melanoma vs metastatic melanoma (GDS3966, [46]).

\section{Statistical analysis}

Data are expressed as mean \pm S.D. (unless differently specified) from at least three independent experiments. For in vitro studies, statistical analysis was performed using Student's t-test or one-way ANOVA test when 
indicated. When needed, normal distribution was calculated by D'Agostino-Pearson omnibus normality test. $P$ value $\leq 0.01$ was considered the statistically significant threshold, unless differently specified.

SIRT2 activity data were analyzed with GraphPad Prism 5 (GraphPad Software Inc.) software as follows: upon log-transformation of the concentration data, nonlinear regression was carried out, choosing standard curve, dose-response stimulation, log (agonist) vs response and EC50 value calculation was carried out. For in vivo experiments Mann-Whitney $U$ test for independent samples was used to evaluate the statistical significance of the difference between groups. Mouse survival was analyzed by the Kaplan-Meier method. The survival distributions of treatment groups were compared with the log-rank test. Differences in $p$ values of 0.05 or less were considered significant. Statistical analyses were performed on GraphPad Prism 5 (GraphPad Software Inc.) and MedCalc software (MedCalc Software Ltd).

\section{Results}

Effect of NAM on human melanoma cells number

A375 and SK-MEL-28 cells were treated with increasing NAM doses $(1,20$, and $50 \mathrm{mM})$, in the presence of $10 \%$ FBS. The cell number was counted at 24 and $48 \mathrm{~h}$. Figure $1 \mathrm{a}$ and $\mathrm{c}$ show that NAM significantly reduces cell number in a dose-dependent manner with a strong inhibitory effect at $20 \mathrm{mM}$ and an almost complete effect at $50 \mathrm{mM}$ concentration. Figure 2 shows a representative field of A375 treated with NAM 20 and $50 \mathrm{mM}$ at 24 and $48 \mathrm{~h}$. Supplementary Figure 1 depicts a representative field of SK-MEL-28.

Significant increase of cell death was also observed at 24 and $48 \mathrm{~h}$ in both A375 and SK-MEL-28 cells (Fig. 1b, d). These data indicate a strong dose- and timedependent anti-melanoma effect on both human melanoma cells, in the presence of $10 \%$ FBS. The inhibitory effects at $48 \mathrm{~h}$ depicted in panel $\mathrm{A}$ and $\mathrm{C}$ are more evident in A375 cells, which are more aggressive as compared to SK-MEL-28 cells, according to the Melanoma AGgressiveness Score (MAGS) we recently published [37].

\section{Effect of NAM on cell cycle}

Cells were treated with increasing doses of NAM (10, 20 , and $50 \mathrm{mM}$ ) and the effect on the cell cycle distribution was investigated at $24 \mathrm{~h}$. Figure 3 shows that A375 cells undergo significant accumulation in G1 phase, significant reduction in $\mathrm{S}$ phase, and significant increase in the sub-G1 (apoptosis) phase (panels A, B, D
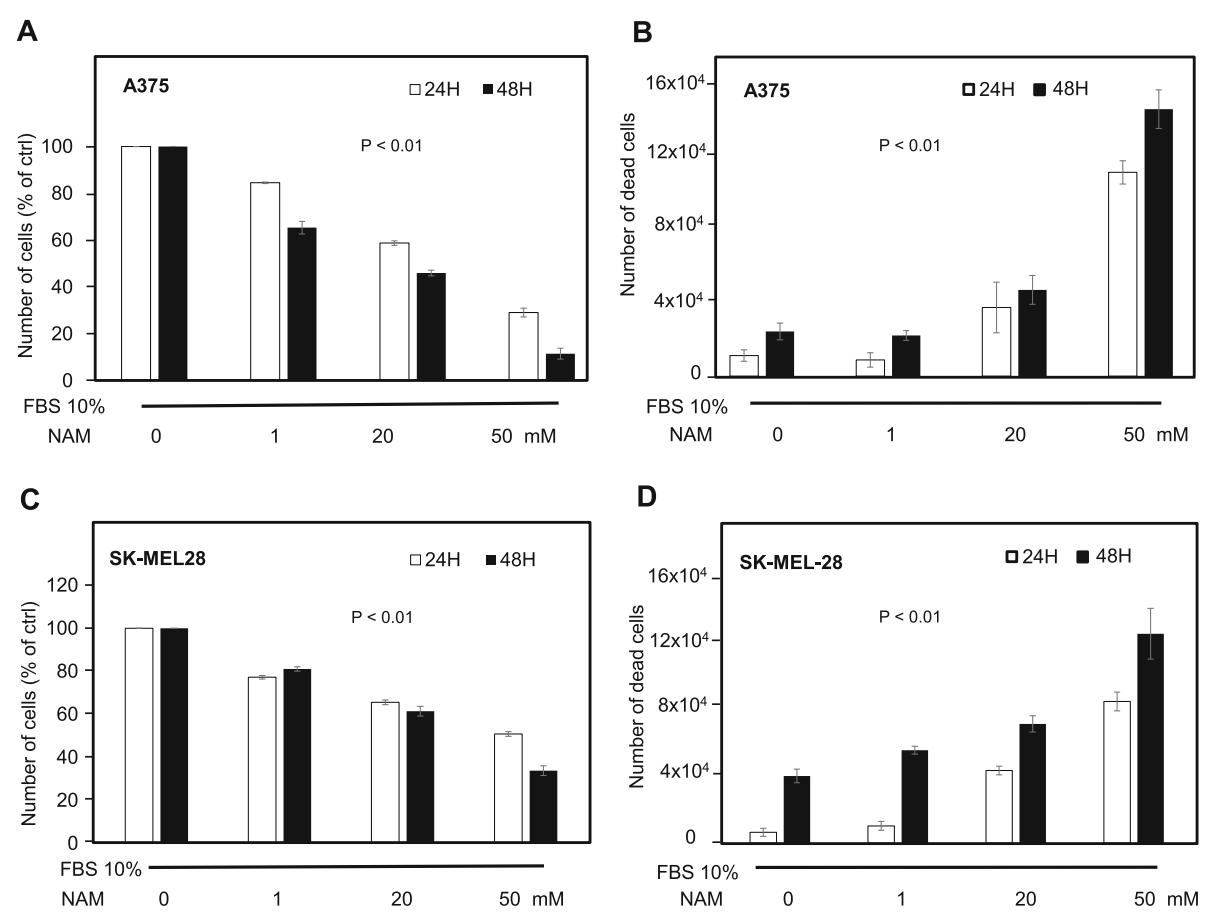

Fig. 1 Cell number and cell death of human melanoma cells treated with increasing NAM concentrations. a, c: A375 and SK-MEL-28 cells were counted at 24 and $48 \mathrm{~h}$ following NAM treatment $(1,20,50 \mathrm{mM})$. A375 $\left(8 \times 10^{4}\right)$ and SK-MEL-28 $\left(1 \times 10^{5}\right)$ cells were plated in p35 Petri dishes at time 0. Data are expressed as percentage of untreated cells. $\mathbf{b}$, $\mathbf{d}$ : Cell death was quantified according to trypan blue exclusion assay and expressed as absolute numbers. All data are expressed as mean \pm S.D. of three independent experiments. In each panel, statistical difference was achieved by one-way ANOVA test 


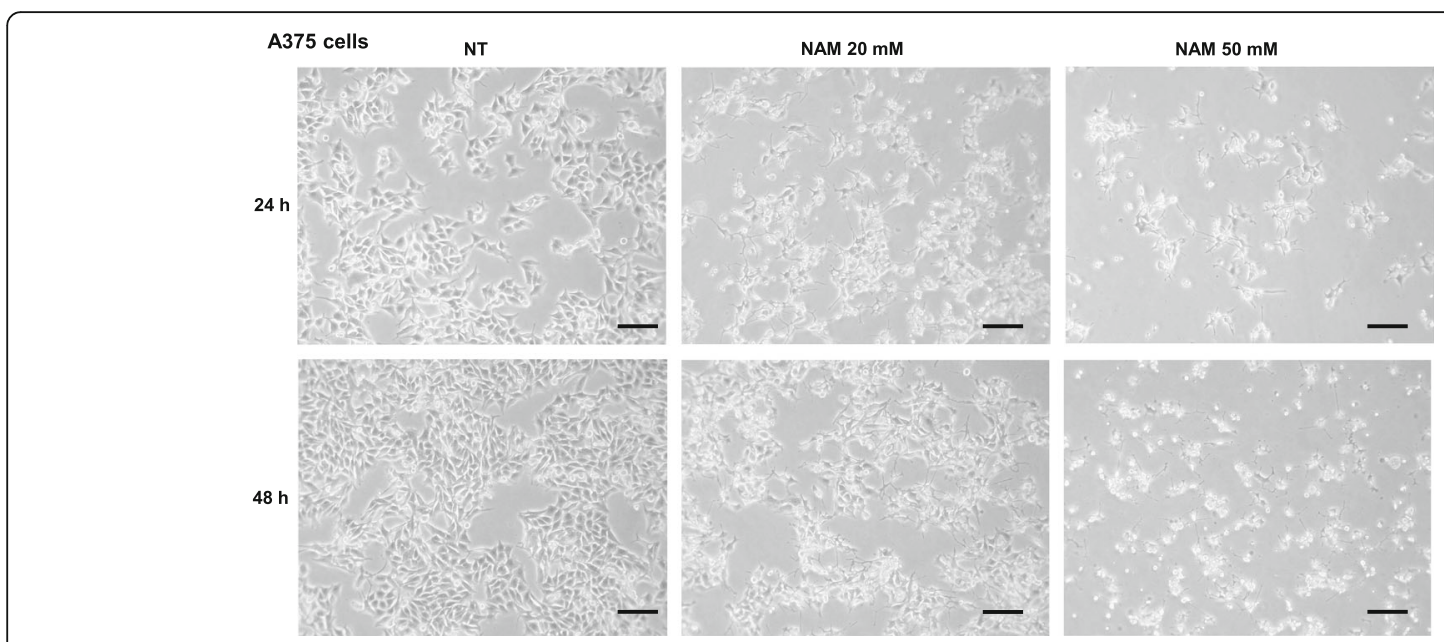

Fig. 2 Representative images of A375. Representative fields showing A375 untreated (NT) or treated with NAM 20 and 50 mM for 24 and 48 h. (100x magnification). Scale bar $=50 \mu \mathrm{M}$

respectively), according to one-way ANOVA test. Panels $\mathrm{E}$ to $\mathrm{H}$ show a representative experiment at each dose.

\section{$\mathrm{NAD}^{+}, \mathrm{ATP}$ and ROS levels in A375 and SK-MEL-28 following short-term NAM treatment}

$\mathrm{NAD}^{+}$, ATP, and ROS levels were measured in A375 and SK-MEL-28 cells. Figure $4 \mathrm{a}$ and d show that NAD ${ }^{+}$ is significantly increased upon $6 \mathrm{~h}$ treatment (at 1,20 , and $50 \mathrm{mM}$ ) in both cell types in a dose-dependent manner. Figure $4 \mathrm{~b}$ and $\mathrm{e}$ show a parallel increase of intracellular ATP at $6 \mathrm{~h}$. Finally, Fig. 4c and f show a significant increase of ROS levels in both cell types, upon 6 $\mathrm{h}$ treatment with $50 \mathrm{mM}$ NAM. These data indicate that NAM exerts early strong metabolic effects.

\section{NAM effects on mouse B16-F10 cell number, cell death, and ROS levels}

We then investigated the in vitro effects of NAM in a mouse melanoma cell line. Figure $5 \mathrm{a}$ and b show a significant and time-dependent cell growth reduction and
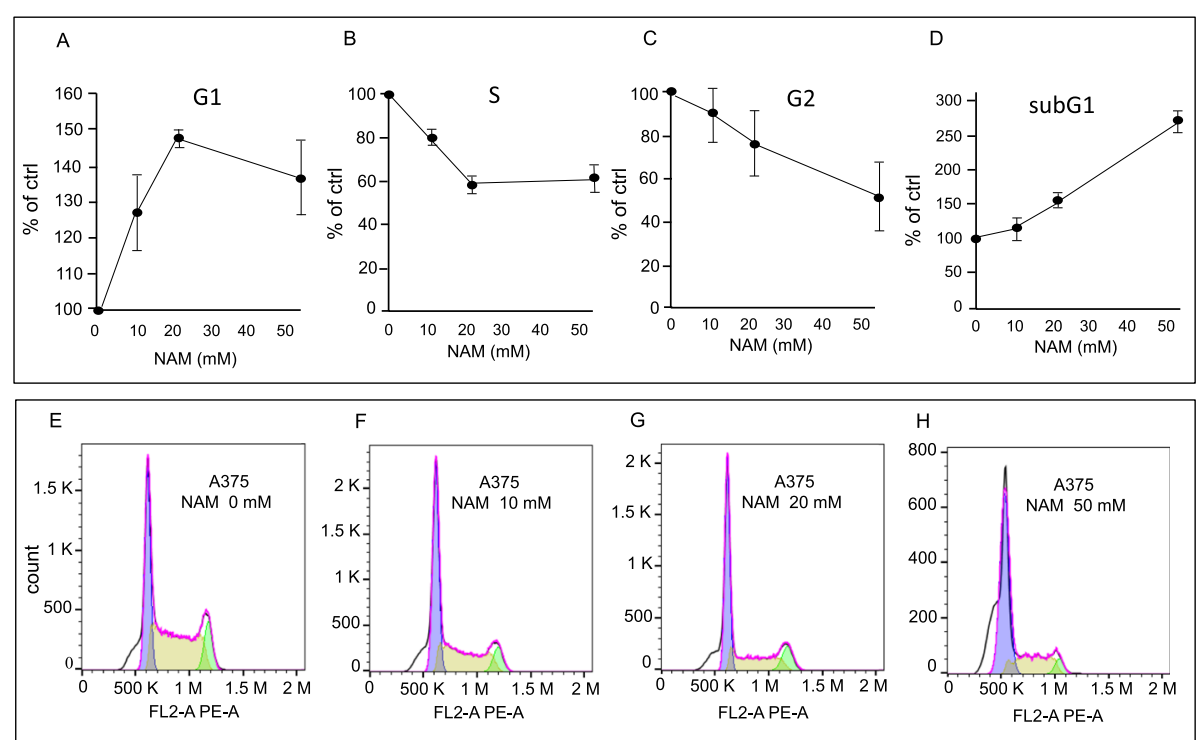

Fig. 3 Cell cycle analysis of A375 cells treated with increasing doses of NAM. A375 cells were plated $\left(8 \times 10^{4}\right.$ cells/plate) in p35 Petri dishes at time 0 and were then starved for $18 \mathrm{~h}$ in serum-free medium. Cells were then treated with 0, 10, 20, and $50 \mathrm{mM}$ NAM, for $24 \mathrm{~h}$, in the presence of FBS $10 \%$. Panels $\mathbf{a}, \mathbf{b}, \mathbf{c}, \mathbf{d}$ report the mean \pm S.D. of three independent experiments; 10.000 events were acquired. Panels $\mathbf{e}$ to $\mathbf{h}$ show a representative experiment. One-way ANOVA test in panels $\mathbf{a}, \mathbf{b}$ and $\mathbf{d}$ computed a $p<0.05$ 

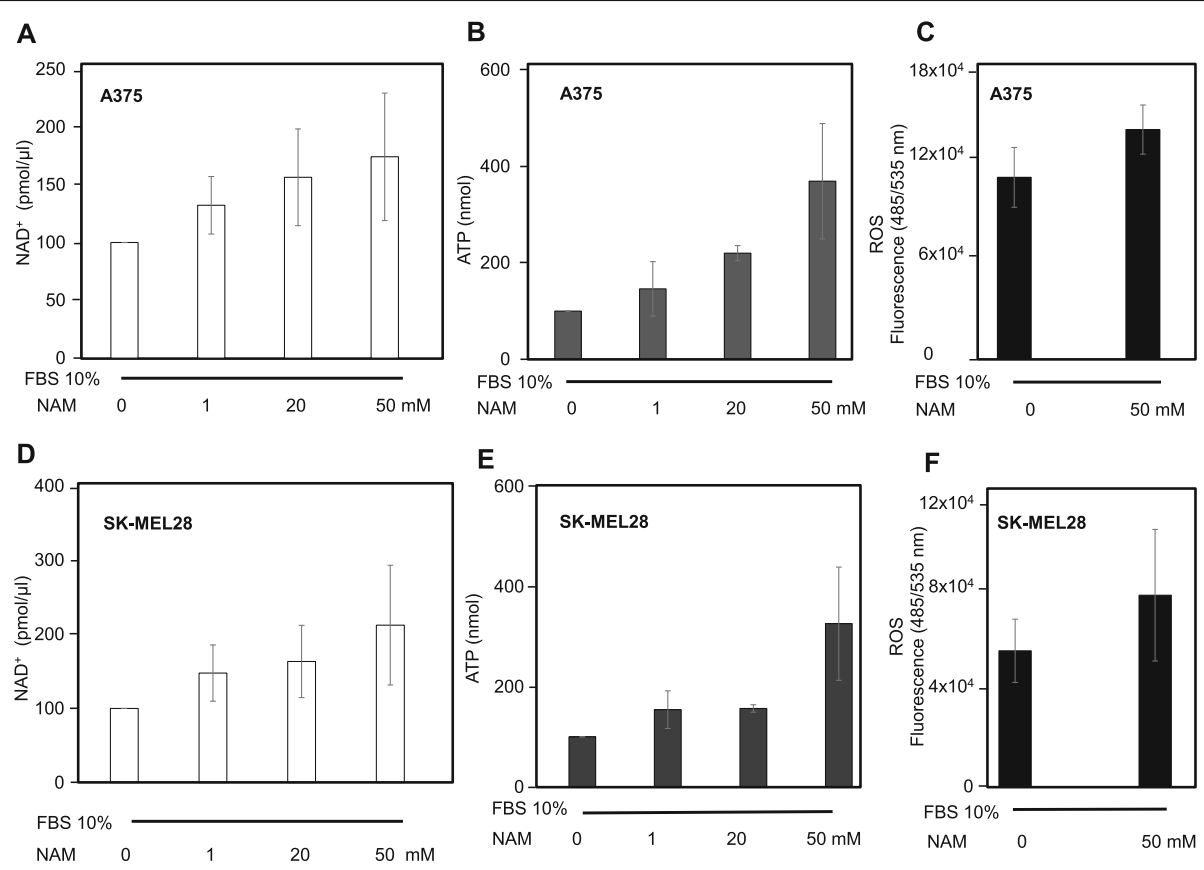

Fig. $4 \mathrm{NAD}^{+}$, ATP, and ROS levels under NAM treatment. $\mathbf{a}, \mathbf{b}$, d, e: NAM treatment increased NAD ${ }^{+}$and ATP levels in both A375 and SK-MEL-28 cells $\left(8 \times 10^{4}\right.$ and $1 \times 10^{5}$ in p35 Petri dishes, respectively) after $6 \mathrm{~h}$ treatment. c, f: NAM increased ROS levels in A375 and SK-MEL-28 cells. The cells $\left(8 \times 10^{4}\right.$ and $1 \times 10^{5}$ in p35 Petri dishes, respectively) were stained with $2^{\prime}, 7^{\prime}$-dichlorodihydroflurescein diacetate (DCFDA) and then treated with $50 \mathrm{mM}$ NAM for $6 \mathrm{~h}$. All data are expressed as mean \pm S.D. of three independent experiments. In panels $\mathbf{a}, \mathbf{b}, \mathbf{d}$, e one-way ANOVA test as statistical assay computed a $p<0.05$. In panels $\mathbf{c}$ and $\mathbf{f}$ a $p<0.05$ was computed, according to Student's t-test

cell-death increase of B16-F10 mouse melanoma cells after NAM treatment $(1,20$, and $50 \mathrm{mM})$; Fig. $5 \mathrm{c}$ shows a significant increase of ROS levels after $6 \mathrm{~h}$ treatment with NAM $50 \mathrm{mM}$. Figure $5 \mathrm{~d}$ shows a representative field of B16-F10 cells treated with NAM $50 \mathrm{mM}$ at 24 and $48 \mathrm{~h}$. These data indicate that NAM anti-melanoma effects observed in human cells are confirmed in mouse melanoma cells.

\section{Sirtuin 2 (SIRT2) activity in vitro upon NAM treatment;} SIRT2 transcriptomic analysis in silico

NAM effect on purified SIRT2 was then evaluated by an in vitro activity assay. Panel A of Fig. 6 shows that increasing NAM concentrations ranging from $0.01 \mathrm{mM}$ up to $20 \mathrm{mM}$ lead to a dose-dependent inhibition of SIRT2 enzymatic in vitro activity after $1 \mathrm{~h}$ incubation time. The computed EC50 was $2 \mu \mathrm{M}$. These data led us to hypothesize that inhibition of SIRT2 by NAM may underly, at least in part, the observed anti-melanoma effects. Sirtuins are indicated as possible therapeutic targets in different cancer types. According to expression values reported in GENT2 database, we report here for the first time that SIRT2 expression is significantly increased $(p<0.0002)$ in metastatic melanoma patients (expression value $8.3+0.43$ in 148 patients) as compared to controls (expression value $8.09+0.59$, in 211 healthy subjects). This finding was validated in a different database, namely the "Pan-Cancer Analysis of Whole Genomes" reported by the Expression Atlas at EBI [42]. Panel B of Fig. 6 shows that SIRT2 expression in 36 melanoma samples is strongly increased as compared to sun-exposed and sun-non exposed normal skin. Furthermore, SIRT2 shows the highest expression value in 8 melanoma cell lines (including SK-MEL-28) as compared to several other cancer lines (Panel C of Fig. 6). Furthermore, SIRT2 expression level significantly relates to an improved overall survival while the expression of other sirtuins shows no significant relation (see Table 1). Overall patients' survival is depicted in Panel D of Fig. 6: patients with higher expression show lower survival with a strong and significant Hazard Ratio for patients with high expression $(\mathrm{HR}=1.9, p=0.0004)$. Altogether these data indicate that SIRT2 expression is increased in melanoma and patients with lower expression show improved survival.

In vivo NAM antitumor activity in a murine metastatic melanoma model

B16-F10 melanoma cells $\left(3 \times 10^{5}\right)$ were transplanted into C57BL/6 mice. Dose-response experiments were carried out to evaluate the antitumor efficacy and the toxicity of three NAM doses administered systemically (i.p.). Sixteen mice, divided into four groups (4 mice per group), were treated i.p. with NAM 1000, 1500 and $1800 \mathrm{mg} / \mathrm{Kg}$ 

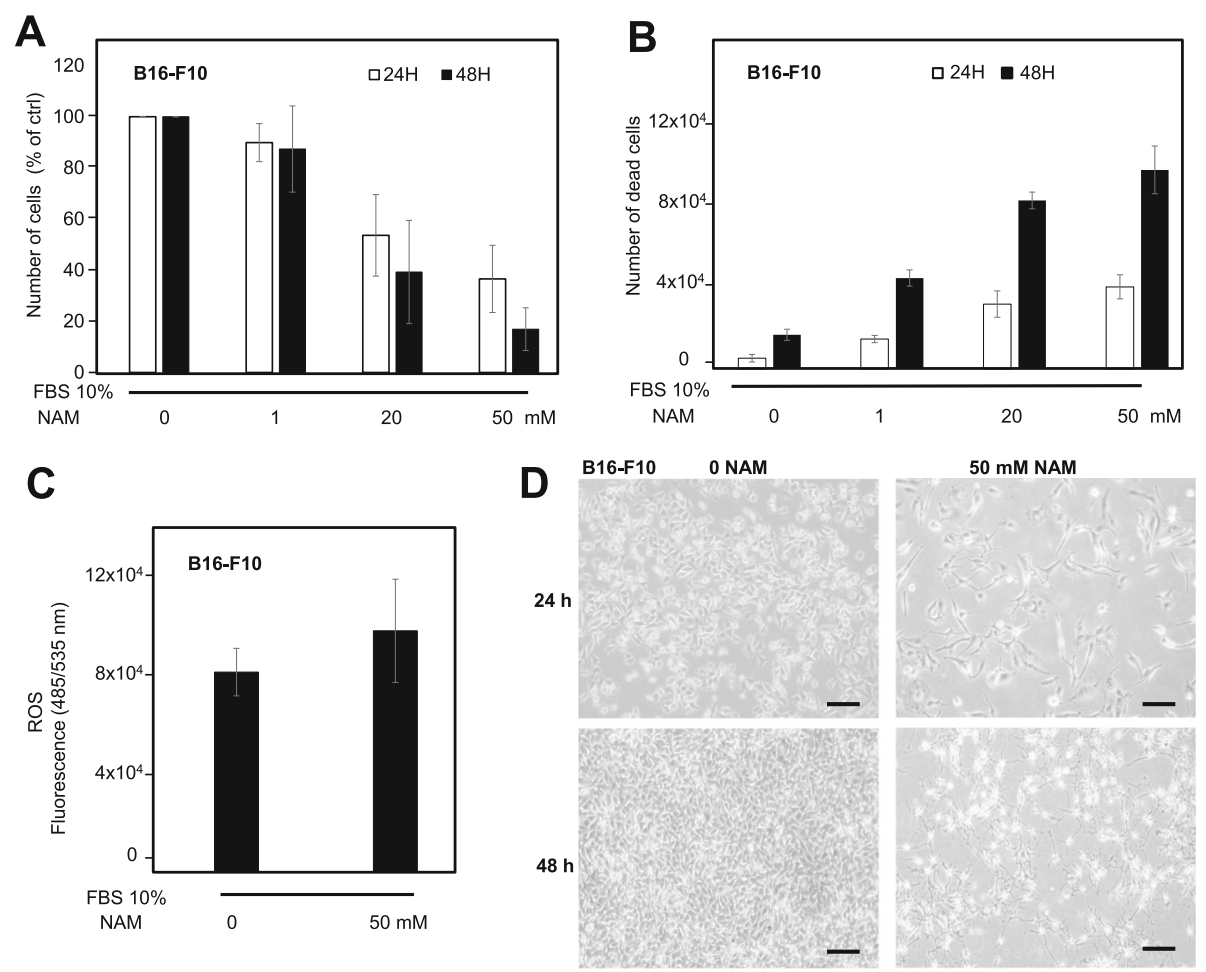

Fig. 5 NAM effects on mouse B16-F10 melanoma cells. a: B16-F10 cells were counted after NAM treatment for 24 and 48 h. B16-F10 cells $\left(8 \times 10^{4}\right)$ were plated in p35 Petri dishes at time 0 , in the presence of $10 \%$ FBS. Cell number is significantly reduced in a dose-dependent manner. Data are expressed as percentage of untreated cells. b: Quantification of cell death by trypan blue exclusion assay, expressed as absolute numbers. c: ROS levels evaluated by 2',7'- dichlorodihydrofluorescin diacetate (DCFDA) staining in cells treated with $50 \mathrm{mM}$ NAM for $6 \mathrm{~h}$. d: Representative fields of B16-F10 cells treated with NAM $50 \mathrm{mM}$ for 24 and $48 \mathrm{~h}$ are shown (100x magnification). Scale bar $=50 \mu \mathrm{m}$. All data are expressed as mean \pm S.D. of three independent experiments. In panels $\mathbf{a}$ and $\mathbf{b}$ one-way ANOVA test computed a $p<0.05$. In panel $\mathbf{c}$ Student's t-test computed a $p<0.05$

or with saline as a control, for 5 days per week, followed by 2 -day rest. Figure 7 a shows tumor growth curves in the 4 groups. At 1500 and $1800 \mathrm{mg} / \mathrm{Kg}$, NAM significantly delayed tumor growth (Fig. 7a). Mouse body weight was monitored twice a week as an indication of NAM toxicity. Mice were also inspected for signs of distress. Figure $7 \mathrm{~b}$ shows that NAM administration did not alter significantly the mouse body weight. Nevertheless, all mice were sleepy for a few hours after treatment regardless of the dose used. An additional set of experiments was carried out: nineteen mice were treated i.p. seven days per week with $1800 \mathrm{mg} / \mathrm{Kg}$ of NAM $(n=10)$ or saline as control $(n=9)$. Figure 8 a shows the mean tumor growth curves of saline- vs NAM-treated mice. A significant $(p<0.01)$ delay of tumor growth was observed in NAM-treated mice at all time points. Panels B and C of Fig. 8 show the growth curves of saline-treated and NAM-treated individual mice, respectively. While in control mice the mean tumor diameters ranged between 1 and $6.5 \mathrm{~mm} 6$ days following tumor implant and between 2 and $10 \mathrm{~mm}$ at day 9 (Fig. 8b), the tumors were palpable only in two NAM-treated mice at day 6 and were all $\leq 2 \mathrm{~mm}$ at day 9 (Fig. 8c). Following day 9, tumors grew in 8 out of 10 NAM-treated mice even if the difference in size with saline-treated mice was still significant. Of special note, in 2 NAM-treated mice the tumor diameter was only $1 \mathrm{~mm}$ up to 20 days following tumor implant, indicating a long-lasting antitumor effect (Fig. 8c). Interestingly, in these two mice treatment discontinuation led to tumor regrowth (Fig. 8e). Figure 8d shows the Kaplan-Meier survival plots in saline- vs NAM-treated tumor-bearing mice. The endpoint used for survival analyses was the day when the tumors reached a mean diameter $\geq 12 \mathrm{~mm}$ or the day of euthanasia (mice with necrotic tumor, weight loss, or sign of distress). The survival curve of NAM-treated mice was significantly different from the curve of control mice. Starting from day 9 to day 17 following tumor implant all saline-treated mice reached the endpoint. On the contrary, NAM-treated mice reached the endpoint starting from day 17 and $20 \%$ of mice did not reach the endpoint while on treatment. The toxicity of the sevendays-per-week administration schedule was like that of the 5-days-per-week schedule (data not shown). Overall, these data indicate that NAM treatment induces a significant, dose-dependent delay of tumor growth in a 
A

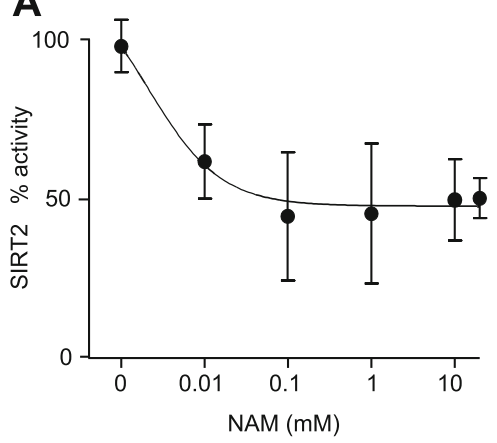

C

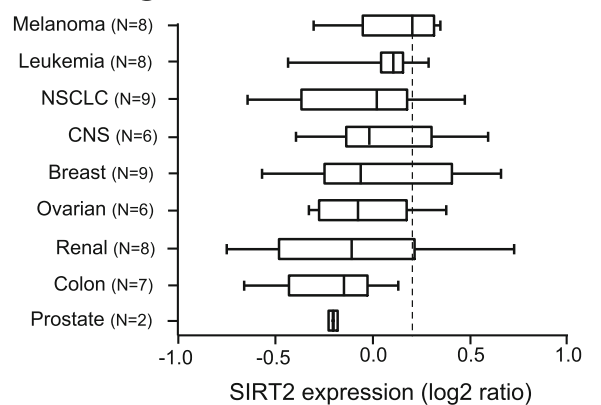

B

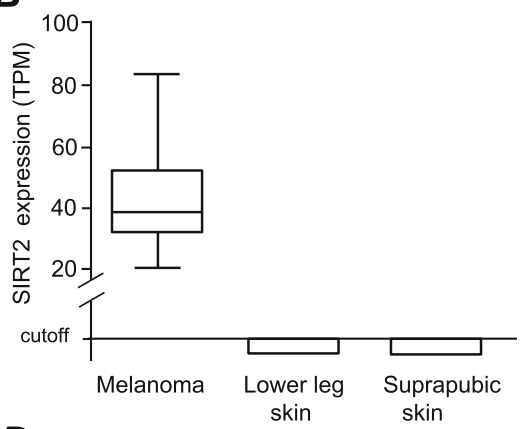

D

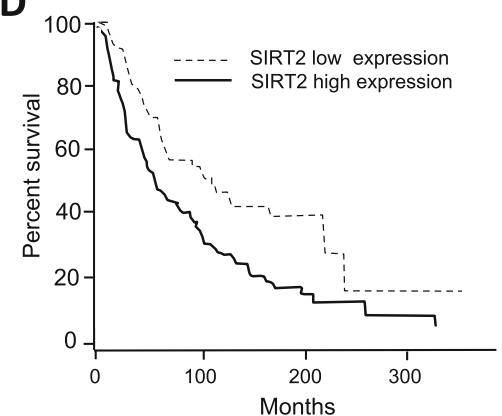

Fig. 6 SIRT2 transcription in silico analysis and in vitro activity assay. a. SIRT2 in vitro activity upon NAM treatment. The activity was measured with the SIRT2 Inhibitor Screening Assay Kit (Fluorometric) (BioVision), as reported in Methods section. After $1 \mathrm{~h}$ incubation at $37^{\circ} \mathrm{C}$, the in vitro activity was found to be reduced by NAM in a dose-dependent manner. b: Expression level of SIRT2 in melanoma vs normal skin, according to "Pan-Cancer Analysis of Whole Genomes" reported by the Expression Atlas at EBI [42] (https://www.ebi.ac.uk/gxa/home). SIRT2 expression is strongly increased in melanoma as compared to control skin. c. The expression level of SIRT2 in NCl-60 human cancer cells lines, from GEO dataset GDS1761. Melanoma shows the highest median expression of SIRT2, according to the expression values in 8 human cell lines (namely LOXIMVI, M14, MALME-3 M, SK-MEL-28, SK-MEL-2, SK-MEL-5, UACC257, UACC62). Box \& whisker plot reports median and 5-95 percentile. d. Overall survival in melanoma patients as a function of SIRT2 expression, according to expression data reported in GEPIA2 database; overall survival is computed from quartile distribution (the cutoff for high expression was set to 70\%; cutoff for low expression set to 25\%). Significant improvement of overall survival is observed in patients expressing low-levels of SIRT2 (HR $=1.9, p=0.0004)$

metastatic tumor model; $1800 \mathrm{mg} / \mathrm{Kg}$ treatment also induces a significant increase in the survival of tumorbearing mice.

\section{In vivo immunostimulating effects of NAM treatment}

Since NAM administration is known to reduce UVmediated immunosuppression [47], we explored whether NAM affected some components of the anti-tumor immune response. We compared the frequency of IFN- $\gamma$ producing cells in the blood of NAM-treated $(1800 \mathrm{mg} /$ $\mathrm{Kg}$ ) and saline-treated (ctr) tumor-bearing mice (Fig. 9a). The mice were the same of the experiments depicted in Fig. 8. Fourteen days following the tumor implant (i.e. at a time point when the tumor growth curves were significantly different), blood was collected by individual mice and IFN- $\gamma$ ELISPOT assay was conducted to evaluate the response against irradiated (20 Gy) B16-F10 cells. Medium or concanavalin A were used as negative and

Table 1 Relation of SIRT1, SIRT2, SIRT3, SIRT4, SIRT5, SIRT6, and SIRT7 expression with overall survival Hazard Ratio in melanoma patients, according to data reported in GEPIA2 database [43]. SIRT2 shows strong and significant HR

\begin{tabular}{lllll}
\hline Gene name & Hazard Ratio for high expression & $\boldsymbol{P}$ & N. of patients with high expression & N. of patients with low expression \\
\hline SIRT1 & 0.72 & 0.074 & 138 & 114 \\
SIRT2 & 1.9 & 0.0004 & 138 & 115 \\
SIRT3 & 0.75 & 0.12 & 138 & 114 \\
SIRT4 & 0.91 & 0.6 & 137 & 109 \\
SIRT5 & 0.98 & 0.93 & 138 & 115 \\
SIRT6 & 0.98 & 0.93 & 138 & 115 \\
SIRT7 & 0.91 & 0.63 & 138 & 115 \\
\hline
\end{tabular}



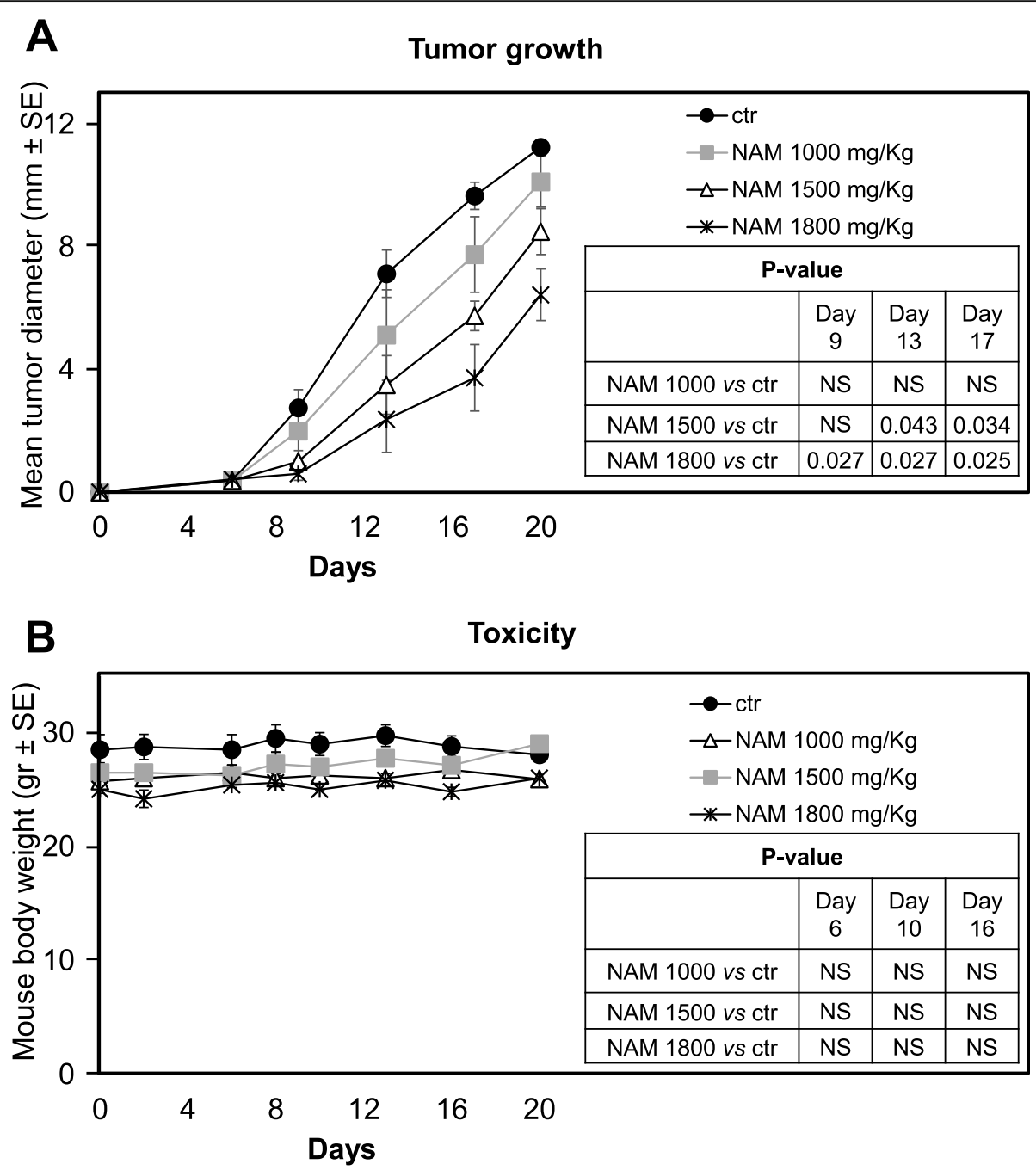

Fig. 7 Antitumor effect and toxicity of NAM administered 5 days per week, i.p. C57BL/6 mice were injected s.c. with $3 \times 10^{5}$ B16-F10 cells. Mice were divided into four groups $(n=4)$ and treated i.p. with NAM 1000 (grey square), 1500 (open triangle) or 1800 (asterisk) mg/Kg or with saline (ctr, black circle), as indicated, starting from the same day of tumor implant for 5 days per week. a: Tumor growth was monitored twice a week with a digital caliper. Data are reported as the average of the mean tumor diameter of 4 mice per group \pm S.E. b: Mouse body weight was monitored twice a week as an indication of NAM toxicity. Data are reported as mean weight of 4 mice per group \pm S.E. P-values were calculated by Mann-Whitney $U$ test for independent samples (NS, not significant)

positive control, respectively. Figure 9a shows that in both saline- and NAM-treated mice a significant production of IFN- $\gamma$ in response to irradiated melanoma tumor cells was observed, indicating the presence of a spontaneous anti-tumor immune response. Remarkably, in NAM-treated mice the frequency of IFN- $\gamma$ producing cells was significantly higher than in control mice. These data indicate that NAM treatment affects a key mediator of cell-mediated anti-tumor immunity, such as IFN- $\gamma$.

Then, the plasma levels of 23 cytokines, chemokines, and growth factors were measured in NAMvs saline-treated mice. Plasma was derived from the same blood used for the ELISPOT assay samples (14 days following tumor implant). Figure $9 \mathrm{~b}$ shows that NAM treatment significantly modulates the protein levels of 4 cytokines and 2 chemokines in the plasma of tumor-bearing mice, namely, IL-3, IL-5, IL-10, IL12(p40), Eotaxin and RANTES. Eotaxin and IL-5 were significantly increased in NAM-treated mice, whereas IL-3, IL-12(p40), RANTES and IL-10 protein levels were significantly reduced.

Increased levels of IL-5 and Eotaxin may suggest an effect of NAM on CD4 $4^{+}$Th2 cells and on eosinophils [48]. Altogether these data show that NAM treatment of tumor-bearing mice induces immunomodulation affecting different immune subsets. 

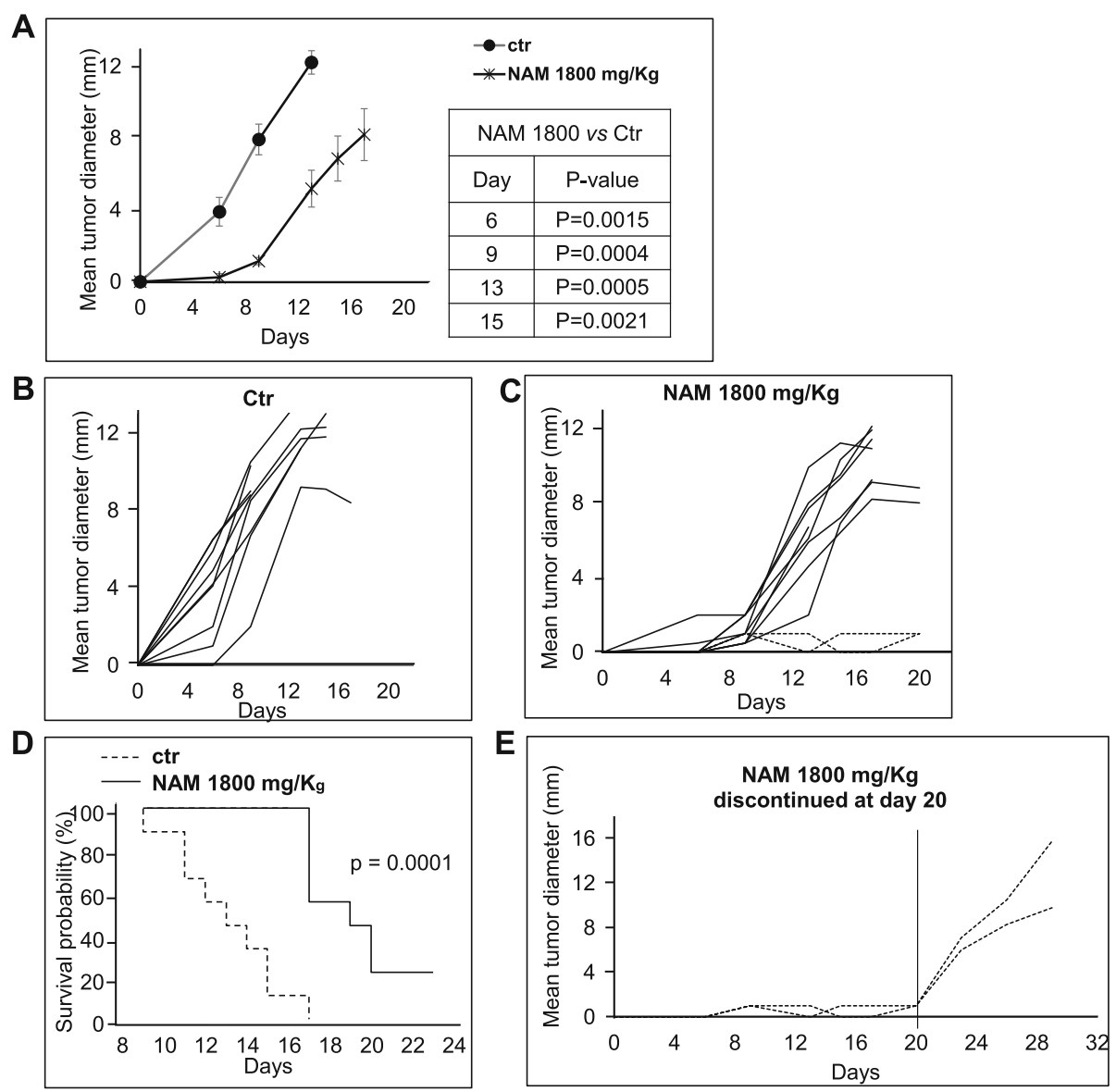

Fig. 8 Antitumor efficacy of NAM $1800 \mathrm{mg} / \mathrm{Kg}$ administered every day, i.p. C57BL/6 mice were injected s.c. with $3 \times 10^{5}$ B16-F10 cells. Mice were divided in two groups and treated i.p. with NAM $1800 \mathrm{mg} / \mathrm{Kg}(n=10)$ or with saline (ctr) $(n=9)$, as indicated, starting from the same day of tumor implant for 7 days per week. Tumor growth was monitored twice a week with a digital caliper. P-values were calculated by Mann-Whitney $\mathrm{U}$ test for independent samples. a: Data are reported as the average of the mean tumor diameter of 10 or 9 mice per group \pm S.E. $\mathbf{b}$, c: Data are reported as mean tumor diameter of each individual mouse. $\mathbf{d}$ : Kaplan-Meier survival plots of saline- (dashed line) or NAM-treated (solid line) tumor-bearing mice. The endpoint used for survival analyses was the day when the tumors reached a mean diameter $\geq 12 \mathrm{~mm}$ or the day of euthanasia (mice with necrotic tumor, weight loss, or sign of distress). P-values were calculated using the log-rank test. e: Tumor growth of two NAM-treated mice (same as in C) after treatment discontinuation at day 20

Expression levels of niacin receptors in human melanoma specimens

NAM is normally acquired via the daily diet; we hypothesized that the daily protecting action of NAM may be reduced or absent in melanoma patients. NAM deamidation produces Nicotinic acid which acts via the highand low- affinity receptors HCAR2 and HCAR3. We analyzed the expression levels of HCAR2 and HCAR3 in GEPIA2 database and on the independent GEO database, in a total of 1172 patients. GEPIA2 analysis indicated a strong reduction of HCAR2 and HCAR3 expression in melanoma patients as compared to normal skin controls. HCAR1 is an additional receptor isoform and has low expression levels in both normal skin and in melanoma samples (Fig. 10a, b, c). Furthermore, their expression levels were analyzed by PCA (Principal Component Analysis). Panel D of Fig. 10 shows the three- dimensional space defined by the 3 variance components associated with the expression values of these receptors. When observed in this space, a striking separation between melanoma and healthy controls is evident.

Expression data of Niacin receptors were then investigated in the independent database GEO [44] (available at https://www.ncbi.nlm.nih.gov/gds). It only reports the expression values of HCAR3. Supplemental Figure 2 shows a strong and significant reduction of the expression levels in melanoma samples as compared to control skin (from dataset GDS1375), and a strong and significant reduction in metastatic melanoma samples as compared to primary melanoma samples (from dataset GDS3966), therefore confirming the expression data observed in GEPIA2 database.

These data indicate that Niacin receptors expression is strongly reduced in melanoma patients suggesting that 


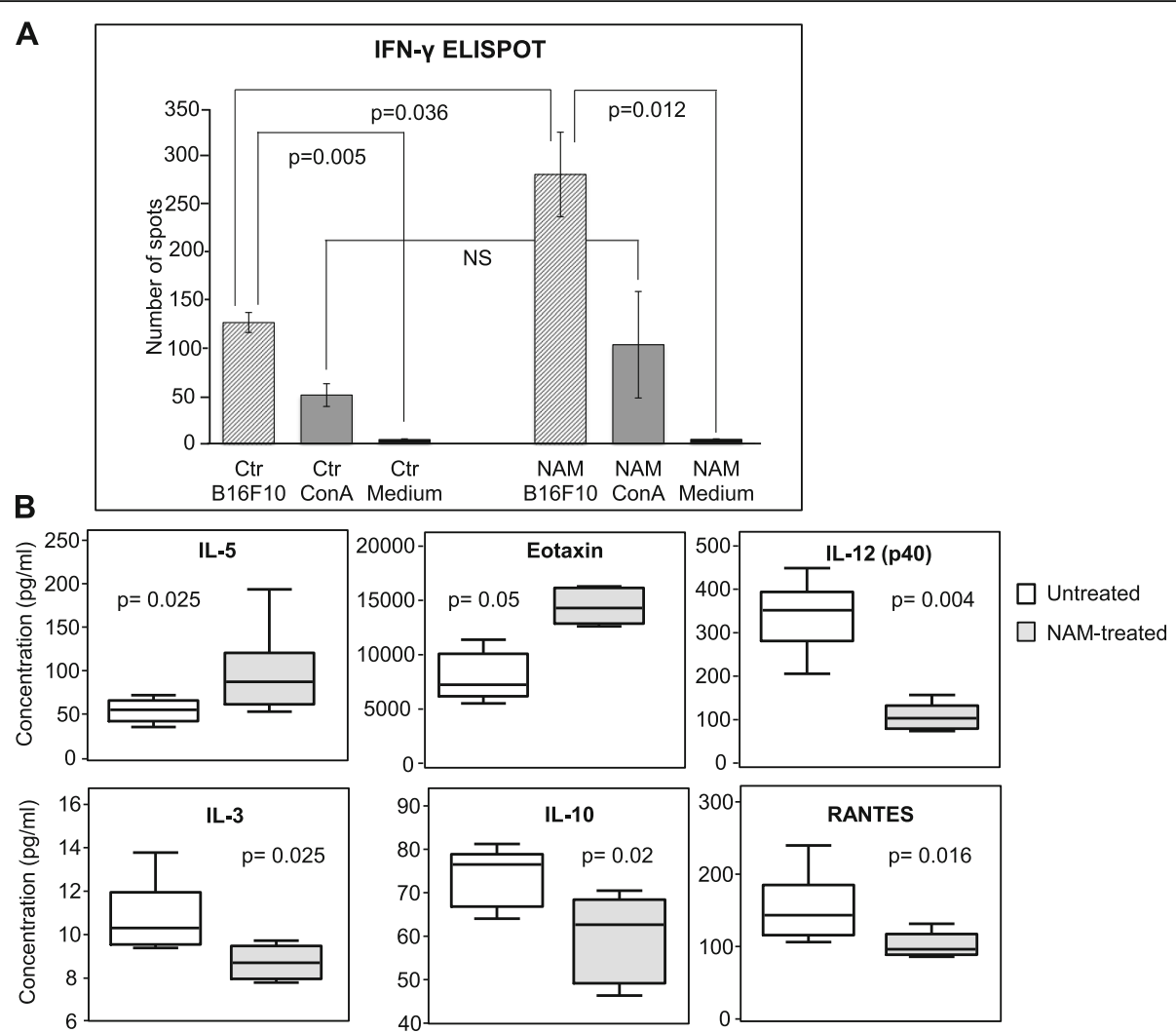

Fig. 9 NAM treatment induces an anti-tumor immune response and cytokine/chemokine modulation. C57BL/6 mice were transplanted with B16F10 tumor cells and treated every day with NAM $(1800 \mathrm{mg} / \mathrm{Kg})$ as in Fig. 8. a: The frequency of interferon (IFN)- $\gamma$ producing cells in the blood of mice treated with saline (ctr) or with NAM was analyzed 14 days after tumor implant. Blood was collected by individual mice $(n=6)$ and IFN- $\gamma$ ELISPOT assay was conducted to evaluate the response against irradiated (20 Gy) B16-F10 cells. Medium or concanavalin A (ConA) $(5 \mu \mathrm{g} / \mathrm{ml})$ were used as negative and positive control, respectively. Data represent the mean ( \pm S.E.) of 6 individual mice tested in triplicate. P-values were calculated by Mann-Whitney $U$ test for independent samples. b: NAM treatment significantly modulates the protein levels of cytokines and chemokines in the plasma of tumor-bearing mice. The protein level of 23 cytokines, chemokines, and growth factors was analyzed by Bio-Plex cytokine assay in saline- (white boxplot) or NAM-treated (grey boxplot) mice. The boxplots contain median values (horizontal line), interquartile range (the box length), highest and smallest values (whiskers) of the plasma concentration $(\mathrm{pg} / \mathrm{ml})$ of the indicated cytokine or chemokine measured in 6 individual mice per group. $P$ values were calculated by Mann-Whitney $U$ test for independent samples

the physiological protective action of NAM may be reduced in melanoma patients due, at least in part, to the strong reduction of these receptors.

\section{Discussion}

Advanced melanoma patients have different therapeutic options including immunotherapy and targeted therapy. However, the onset of resistance and of severe side effects limit the percentage of patients with long-lasting responses. It is therefore urgent to identify new effective approaches [49]. NAM has beneficial therapeutic effects on joints, pancreatic beta cells, kidney and skin. It reduces acne severity and reduces the incidence of many types of non-melanoma skin cancers and keratoses [50]. NAM shows different, even opposite, effects at low vs high doses. In fact, at doses near to $5 \mathrm{mM}$ NAM shows cell protection activity improving viability and replication potential of cells in culture, while at doses above 20
$\mathrm{mM}$, it causes apoptotic death, with an IC50 of $21.5 \mathrm{mM}$ [23]. In the present study, NAM showed a strong and significant antiproliferation effect on A375 and SKMEL-28 melanoma cells, two human melanoma cell lines characterized for high and low aggressiveness, respectively [37]. NAM was tested in the $\mathrm{mM}$ concentration range since similar high concentrations have recently shown activity in melanoma cells [23] and in colon cancer cells [51]. In the latter cells low- and highdoses of NAM show opposite effects; micromolar doses appear to be cell-protective while millimolar doses induce cell death, likely related to the oxidative stress [51]. Cell killing effects of high NAM doses were also observed in C. elegans with defective activity of nicotinamidase PNC-1, where NAM levels increase tenfold [52].

NAM is known to play an important role in energy production and metabolism [53] and is reported to increase $\mathrm{NAD}^{+}$and ATP levels in skin cells $[12,53]$. Data 

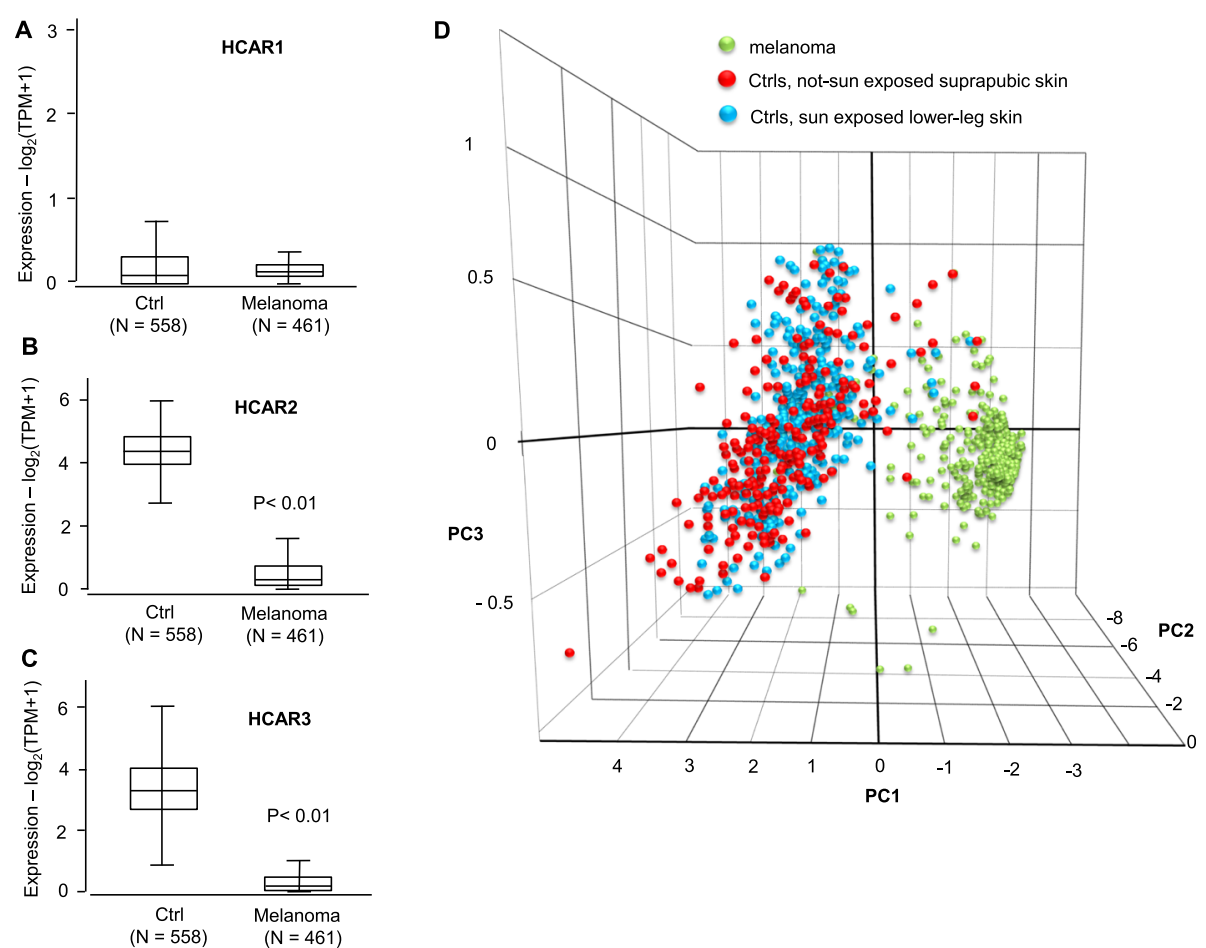

Fig. 10 Expression level of Niacin receptors HCAR2 and HCAR3. $\mathbf{a}, \mathbf{b}$, and $\mathbf{c}$ : expression levels of the Niacin receptors HCAR2 and HACR3, and of the other from HCAR1, in 558 controls and 461 melanoma samples from GEPIA2 database. All three forms have very low expression levels, significantly different from controls for HCAR2 and HCAR3, i.e. the high- and low- affinity receptors of Nicotinic acid respectively. d: PCA analysis of the combined values of HCAR1, HCAR2 and HCAR3 carried out at the link: http://gepia2.cancer-pku.cn/\#dimension. Melanoma samples appear clearly separated from controls in the PCA-made three-dimensional space. $P$ values were calculated by t-Student test

reported in the present study support a mechanism likely related to an early alteration of cellular energy metabolism. In fact, we observed that NAM treatment increases $\mathrm{NAD}^{+}$, ATP, and ROS levels at as early as $6 \mathrm{~h}$ treatment and leads to a significant increase of cells in G1 phase and relevant depletion of cells in S-G2 phase and a strong increase of cells in apoptosis (sub-G1 phase) at $24 \mathrm{~h}$. Of note, NAM has been shown to induce apoptosis also in mouse teratocarcinoma stem cells [54] and increased intracellular levels of ATP have been related to cytotoxic effects in other cell types [55]. All such early effects paralleled the relevant cells number reduction and cell death induction observed at 24 and $48 \mathrm{~h}$ treatment.

ROS are important pathophysiological molecules involved in vital cellular processes. Excessive ROS levels can result in oxidative stress ultimately leading to cell death. ROS homeostasis is often imbalanced in cancer and an elevated oxidative status has been associated with melanoma. In cancer cells, ROS may induce and maintain the oncogenic phenotype and, on the other hand, induce cellular senescence and apoptosis [56]. In this regard, elevated ROS production induced by a chalcone derivative has been shown to significantly reduce melanoma cells viability [57]. Similarly, ROS generation was shown to mediate a proapoptotic activity on human melanoma cells by different molecules, namely chaetocin, a small molecule of fungal origin, and oxalomalate [58, 59]. Data presented in the current study suggest that NAM, via an early effect, directly interferes with melanoma cells metabolism and oxidative stress, indicating a potent anti-melanoma effect besides the well-known ability to reduce non-melanoma skin cancer incidence [11]. In the current study most of the effects observed in human cells were confirmed in mouse melanoma cells B16-F10, namely, reduction of cell growth, induction of cells death and increase of ROS levels.

Sirtuins are interesting molecular targets in melanoma. In mammals, seven homologs are known, namely SIRT1 to SIRT7, ubiquitously expressed and involved in many biological functions such as the control of gene expression, cell cycle, apoptosis, DNA repair, metabolism, and aging. SIRT2 is a cytoplasmic and nuclear protein. While it is downregulated in many cancers such as breast cancer, prostate cancer, human gliomas, neck squamous cell carcinoma, colorectal cancer and leukemia [60-65], we report here, according to other studies [66], that SIRT2 is upregulated in melanoma. In fact, it is reported both as tumor promoter and as tumor suppressor [67]. Karwaciak and colleagues [68] demonstrated that the SIRT2 
inhibitor AC-93253 inhibits the expression of genes involved in the progression and chemoresistance of melanoma, influencing proliferation and apoptosis. They also demonstrated that SIRT2 inhibition makes melanoma cells sensible to dasatinib [69]. Furthermore, SIRT1\&2 knockdown inhibits proliferation and decreases colony formation in melanoma cells [66]. We also report here for the first time a possible role of SIRT2 expression levels on the overall survival of melanoma patients. The EC50 of NAM on SIRT2 activity in vitro was measured here at $2 \mu \mathrm{M}$, suggesting that NAM anti-melanoma activity may be related, at least in part, to the SIRT2 inhibition. As recently reviewed [65], nicotinamide phosphoribosyltransferase (NAMPT) plays a critical role in $\mathrm{NAD}^{+}$synthesis and energy control and its role in melanoma, mediated by BRAF and Sirtuins, is being recognized with increasing evidence. In the present study NAM is reported as a strong SIRT2 inhibitor with an EC50 value, comparable to other inhibitors such as Sirtuin-rearranging ligand (SirReal2) and Thiomyristoyl [70, 71]. NAM doses between 5 and $20 \mathrm{mM}$ are known to induce mitophagy with a mechanism likely related to the $\mathrm{NAD}^{+}$increase [72]; apoptosis and mitophagy were shown to be SIRT2 dependent in the highly aggressive MDA-MB-231 breast cancer cells [73]. We therefore hypothesize that a SIRT2-dependent mitophagy process may occur and further investigation is ongoing in this regard.

The NAM strong effects observed in vitro were paralleled by the relevant effects achieved in vivo. Systemic treatment of melanoma-bearing mice with NAM (1500$1800 \mathrm{mg} / \mathrm{Kg}$ ) significantly inhibited melanoma growth in vivo in a mouse transplanted melanoma model. Previous reports have shown that NAM at low dose $(30 \mathrm{mg} /$ $\mathrm{kg}$ i.p.) is protective in various chemical- and ultraviolet radiation (UVR)-induced carcinogenesis in animal models (reviewed in Reference [66]. On the other hand, at high doses $(1000 \mathrm{mg} / \mathrm{kg}$ i.p.) NAM inhibits the growth of transplanted murine breast adenocarcinoma and carcinogen-induced liver tumors in mice (reviewed in [74]). Here we show a significant dose-dependent antimelanoma effect by daily treatment of tumor-bearing mice with high NAM doses $(1500-1800 \mathrm{mg} / \mathrm{Kg}$ i.p.), no severe toxicity (see Fig. 7b). In addition to delaying tumor growth, $1800 \mathrm{mg} / \mathrm{Kg}$ NAM significantly increased mice survival. Since the reported LD50 in mice is 2500 $\mathrm{mg} / \mathrm{Kg}$ i.v [67]., cautions will be needed to establish the maximum tolerated dose (MTD) in humans due to toxicity risk. By using the body surface area method [75], the mouse dose of $1800 \mathrm{mg} / \mathrm{Kg}$ corresponds to $146 \mathrm{mg} /$ $\mathrm{Kg}$ in humans, i.e. $8.76 \mathrm{~g} /$ day for a $60 \mathrm{~kg}$ person. Although further studies are needed to establish the MTD and the biologically active dose (BAD) in melanoma patients, we do not anticipate severe toxicity. In fact, NAM administration up to $3 \mathrm{~g}$ daily is well tolerated [76]. Mild and transient side effects (such as headache, dizziness, and vomiting) were reported in healthy humans with doses up to $6 \mathrm{~g}$ [77]. Reversible hepatoxicity was observed with $9 \mathrm{~g} /$ day (76). It should be noted also that NAM under our experimental conditions needs to be administered at the beginning of the tumor onset and the treatment needs to be continuous to prevent the tumor regrowth.

Immunohistochemical analysis of melanomas arising in NAM- or placebo-treated patients within the ONTRAC skin cancer chemoprevention trial [11] demonstrated that melanoma lesions occurring in NAMtreated patients were more infiltrated by $\mathrm{CD}^{+}$and $\mathrm{CD}^{+}$lymphocytes than in the placebo, indicating a contribution of the immune response to its pharmacological effect [23].

Since IFN- $\gamma$ is critical for T cell-mediated tumor regression [78], we analyzed the effect of NAM treatment on the frequency of IFN- $\gamma$-secreting cells in response to melanoma cells in PBMCs of tumor-bearing mice. IFN$\gamma$-mediated anti-tumor response was strongly enhanced by NAM. NAM treatment also a significantly reduced the plasmatic levels of IL-3, IL-10, IL-12 and RANTES, and significantly increased IL-5 and Eotaxin levels, suggesting that NAM may trigger a complex modification of the cytokine/chemokine balance. Eotaxin is a potent chemoattractant for eosinophils toward inflammation sites in response to parasitic infections as well as in allergic and autoimmune diseases. Eotaxin binds CCR3 receptor expressed on eosinophils, basophil and Th2 lymphocytes, characterized by the release of Th2 cytokines such as IL-4, IL-5, IL-13, therefore Eotaxin plays a central role in mediating immune response toward a type-2 (Th2) profile [79].

Interestingly, the Th2 cytokine IL-5 was significantly increased in the plasma of NAM-treated melanomabearing mice, while IL-12 (p40), a typical Th1 cytokine, was decreased, indicating a shift toward a Th2 profile in NAM-treated melanoma-bearing mice. Although Th2-mediated immunity has traditionally been viewed as favoring tumor growth, the Th2 immune response was related to an anti-tumor activity especially if associated with eosinophils activation and release of eosinophil-associated cytotoxic granules [80], and Th2 cells were proposed in anticancer adoptive immunotherapy protocols [81]. Remarkably, eosinophilia is emerging as an important biomarker associated with prolonged survival of melanoma patients independently of therapy and in patients treated with checkpoint inhibitors [82].

NAM-treated mice also showed significant reduction of RANTES, IL-10 and IL-3 levels (Fig. 9). RANTES is a pro-inflammatory cytokine with a tumor-promoting role 
[83]; it is expressed in melanoma and is involved in controlling tumor growth and progression [84].

Furthermore, IL-10 has a known immunosuppressive effect in melanoma [85]. IL-3 is a multipotent hematopoietic growth factor produced by activated $\mathrm{T}$ cells, monocytes/macrophages and stroma cells, which was shown to promote tumor angiogenesis [86]. It is possible to speculate that its decreased levels may interfere with the tumor vasculature. Therefore, taken together, reduced levels of RANTES, IL-3 and IL-10 may be involved in the anti-melanoma immune response under NAM treatment.

NAM deamidation produces Nicotinic acid [87], which is known to bind Niacin receptors HCAR2 (or GPR109A or HM74A) and HCAR3 (or GPR109B or HM74B), respectively high- and low- affinity receptors [88]. Their activation has a known anti-inflammatory activity. To our knowledge, Niacin receptors have never been investigated in melanoma. We report here for the first time that expression of Niacin receptors HCAR2 and HCAR3 is almost completely lost in melanoma patients and the PCA (Principal Component Analysis) carried out on the combined expression of Niacin receptors revealed their ability to separate melanoma patients from healthy controls, indicating Niacin receptors as potentially relevant melanoma markers. Additional investigations are necessary on the role of NAM and Niacin receptors; however, according to these preliminary analyses, we argue that the biological effects of NAM and Nicotinic acid mediated by these receptors may play a key role in melanoma patients.

\section{Conclusion}

The current study presents for the first time strong in vitro and in vivo anti-melanoma activity of NAM and several data indicating the underlying molecular mechanisms. NAM daily treatment has been previously shown to play a key role to prevent relapses of non-melanoma skin cancer; the present study gives a strong rationale for further investigations on the role NAM may play in melanoma treatment.

\section{Supplementary information}

Supplementary information accompanies this paper at https://doi.org/10 1186/s13046-020-01719-3.

Additional file 1: Supplementary Figure 1.

Additional file 2: Supplementary Figure 2.

\section{Abbreviations}

NAM: Nicotinamide; ROS: Reactive Oxygen Species; DCFDA: 2',7'dichlorodihydroflurescein diacetate; SIRT1 to SIRT7: Sirtuin 1 to Sirtuin 7; IFN: Interferon; PCA: Principal Component Analysis

\section{Acknowledgments}

We thank Maria Teresa D'Urso and Anna Maria Pacca for help in animal studies. The technical support of the Facility for Complex Protein Mixture (CPM) Analysis at ISS is kindly acknowledged. Claudio Tabolacci was supported by Fondazione Umberto Veronesi that is gratefully acknowledged. The kind support from Dr. Alessandra Boe at ISS - Core Facilities, Istituto Superiore di Sanità, 00161 Rome, Italy is acknowledged.

\section{Authors' contributions}

Conceptualization: FS, FM, DD, EP, FF and AF. Methodology: FS, FM, DD, SR, CT and CG. Validation: SR, CT and CG. Supervision: EP, FF, AF. Writing-review and editing; FS, FM, DD, SR, CT, CG, EP, FF and AF. The author(s) read and approved the final manuscript.

\section{Funding}

This research was funded by Italian Ministry of Health (MOH) RC-2018, RC2019 Line 3.4 to AF.

\section{Availability of data and materials n/a}

\section{Ethics approval and consent to participate}

all human data were from public databases; all mice were treated in accordance with the European Community guidelines and all experiments were approved by the ISS Review Board (Protocol number 986/SSA/13).

\section{Consent for publication}

All authors have read and agree to the manuscript submission.

\section{Competing interests}

Authors declare no conflict of interest.

\section{Author details}

'IDI-IRCCS, Istituto Dermopatico dell'Immacolata, Rome 00167, Italy. ${ }^{2}$ Department of Oncology and Molecular Medicine, Istituto Superiore di Sanità, Rome 00161, Italy. ${ }^{3}$ Unit of Human Anatomy, Department of Anatomy, Histology, Forensic Medicine and Orthopedics, Sapienza University, 00161 Rome, Italy.

Received: 30 July 2020 Accepted: 24 September 2020

Published online: 07 October 2020

\section{References}

1. Buqué A, Bloy N, Kroemer G, Galluzzi L. Potential mechanisms of cancer prevention by nicotinamide. Br J Pharmacol. 2020:bph.15096. https://doi. org/10.1111/bph.15096.

2. Damian DL. Photoprotective effects of nicotinamide. Photochem Photobiol Sci. 2010;9:578. https://doi.org/10.1039/b9pp00146h.

3. Fricker RA, Green EL, Jenkins SI, Griffin SM. The influence of Nicotinamide on health and disease in the central nervous system. Int J Tryptophan Res. 2018;11:117864691877665. https://doi.org/10.1177/1178646918776658.

4. Chi Y, Sauve AA. Nicotinamide riboside, a trace nutrient in foods, is a vitamin B3 with effects on energy metabolism and neuroprotection. Curr Opin Clin Nutr Metab Care. 2013;16:657-61. https://doi.org/10.1097/MCO. ob013e32836510c0

5. Guo S, Chen Q, Sun Y, Chen J. Nicotinamide protects against skeletal muscle atrophy in streptozotocin-induced diabetic mice. Arch Physiol Biochem. 2019;125:470-7. https://doi.org/10.1080/13813455.2019.1638414.

6. Shibata K. Organ co-relationship in tryptophan metabolism and factors that govern the biosynthesis of Nicotinamide from tryptophan. J Nutr Sci Vitaminol (Tokyo). 2018;64:90-8. https://doi.org/10.3177/jnsv.64.90.

7. Badawy AB. Pellagra and alcoholism: a biochemical perspective. Alcohol Alcohol. 2014:49:238-50. https://doi.org/10.1093/alcalc/agu010.

8. Biefer HRC, Vasudevan A, Elkhal A. Aspects of tryptophan and Nicotinamide adenine dinucleotide in immunity: a new twist in an old tale. Int J Tryptophan Res. 2017;10:117864691771349. https://doi.org/10.1177/ 1178646917713491.

9. Takahashi N, Li F, Fushima T, Oyanagi G, Sato E, Oe Y, Sekimoto A, Saigusa D, Sato H, Ito S. Vitamin B3 Nicotinamide: a promising candidate for treating preeclampsia and improving fetal growth. Tohoku J Exp Med. 2018;244:2438. https://doi.org/10.1620/tjem.244.243. 
10. Chen AC, Martin AJ, Dalziell RA, Halliday GM, Damian DL. Oral nicotinamide reduces transepidermal water loss: a randomized controlled trial. $\mathrm{Br} J$ Dermatol. 2016;175:1363-5. https://doi.org/10.1111/bjd.14648.

11. Chen AC, Martin AJ, Choy B, Fernández-Peñas P, Dalziell RA, McKenzie CA, Scolyer RA, Dhillon HM, Vardy JL, Kricker A, et al. A phase 3 randomized trial of Nicotinamide for skin-cancer chemoprevention. N Engl J Med. 2015;373: 1618-26. https://doi.org/10.1056/NEJMoa1506197.

12. Fania L, Mazzanti C, Campione E, Candi E, Abeni D, Dellambra E. Role of nicotinamide in genomic stability and skin cancer chemoprevention. Int J Mol Sci. 2019;20:5946. https://doi.org/10.3390/ijms20235946.

13. Chen AC, Damian DL. Nicotinamide and the skin. Australas J Dermatol. 2014;55:169-75. https://doi.org/10.1111/ajd.12163.

14. Rolfe HM. A review of nicotinamide: treatment of skin diseases and potential side effects. J Cosmet Dermatol. 2014;13:324-8. https://doi.org/10. 1111/jocd.12119.

15. Hasmann M, Schemainda I. FK866, a highly specific noncompetitive inhibitor of nicotinamide phosphoribosyltransferase, represents a novel mechanism for induction of tumor cell apoptosis. Cancer Res. 2003;63:743642.

16. Galli M, Van Gool F, Rongvaux A, Andris F, Leo O. The Nicotinamide Phosphoribosyltransferase: a molecular link between metabolism, inflammation, and cancer. Cancer Res. 2010;70:8-11. https://doi.org/10.1158/ 0008-5472.CAN-09-2465.

17. Dalamaga M, Christodoulatos GS, Mantzoros CS. The role of extracellular and intracellular Nicotinamide phosphoribosyl-transferase in cancer: diagnostic and therapeutic perspectives and challenges. Metabolism. 2018; 82:72-87. https://doi.org/10.1016/j.metabol.2018.01.001.

18. ClinicalTrials.gov. www.ClinicalTrials.gov. Accessed 15 Jan 2020.

19. Minocha R, Damian DL, Halliday GM. Melanoma and nonmelanoma skin cancer chemoprevention: a role for nicotinamide? Photodermatol Photoimmunol Photomed. 2018;34:5-12. https://doi.org/10.1111/phpp.12328.

20. Chen AC, Halliday GM, Damian DL. Non-melanoma skin cancer: carcinogenesis and chemoprevention. Pathology. 2013;45:331-41. https:// doi.org/10.1097/PAT.0b013e32835f515c

21. Snaidr VA, Damian DL, Halliday GM. Nicotinamide for photoprotection and skin cancer chemoprevention: a review of efficacy and safety. Exp Dermatol. 2019;28:15-22. https://doi.org/10.1111/exd.13819.

22. Minocha R, Martin AJ, Chen AC, Scolyer RA, Lyons JG, McKenzie CA, Madore J, Halliday GM, Damian DL. A reduction in inflammatory macrophages may contribute to skin cancer chemoprevention by nicotinamide. J Invest Dermatol. 2019;139:467-9. https://doi.org/10.1016/j.jid.2018.08.018.

23. Malesu R, Martin AJ, Lyons JG, Scolyer RA, Chen AC, McKenzie CA, Madore J, Halliday GM, Damian DL. Nicotinamide for skin cancer chemoprevention: effects of nicotinamide on melanoma in vitro and in vivo. Photochem Photobiol Sci. 2020;19:171-9. https://doi.org/10.1039/C9PP00388F.

24. Itzhaki O, Greenberg E, Shalmon B, Kubi A, Treves AJ, Shapira-Frommer R, Avivi C, Ortenberg R, Ben-Ami E, Schachter J, et al. Nicotinamide inhibits vasculogenic mimicry, an alternative vascularization pathway observed in highly aggressive melanoma. PLoS One. 2013;8:e57160. https://doi.org/10. 1371/journal.pone.0057160.

25. Kunimoto R, Jimbow K, Tanimura A, Sato M, Horimoto K, Hayashi T, Hisahara S, Sugino T, Hirobe T, Yamashita T, et al. SIRT1 regulates Lamellipodium extension and migration of melanoma cells. J Invest Dermatol. 2014;134 1693-700. https://doi.org/10.1038/jid.2014.50.

26. Wilking MJ, Singh CK, Nihal M, Ndiaye MA, Ahmad N. Sirtuin deacetylases: a new target for melanoma management. Cell Cycle. 2014;13:2821-6. https:// doi.org/10.4161/15384101.2014.949085.

27. Hu Z, Fan H, Lv G, Zhou Q, Yang B, Zheng J, Cao W. 5-Aminolevulinic acidmediated sonodynamic therapy induces anti-tumor effects in malignant melanoma via p53-miR-34a-Sirt1 axis. J Dermatol Sci. 2015;79:155-62. https://doi.org/10.1016/j.jdermsci.2015.04.010.

28. George J, Nihal M, Singh CK, Ahmad N. 4'-Bromo-resveratrol, a dual Sirtuin-1 and Sirtuin-3 inhibitor, inhibits melanoma cell growth through mitochondrial metabolic reprogramming. Mol Carcinog. 2019;58:1876-85. https://doi.org/10.1002/mc.23080

29. Nikas IP, Paschou SA, Ryu HS. The role of nicotinamide in cancer chemoprevention and therapy. Biomolecules. 2020;10:477. https://doi.org/ 10.3390/biom10030477.

30. Park J, Halliday GM, Surjana D, Damian DL. Nicotinamide prevents ultraviolet radiation-induced cellular energy loss. Photochem Photobiol. 2010;86:942-8. https://doi.org/10.1111/j.1751-1097.2010.00746.x.
31. Giri B, Belanger K, Seamon M, Bradley E, Purohit S, Chong R, Morgan JC, Baban B, Wakade C. Niacin ameliorates neuro-inflammation in Parkinson's disease via GPR109A. Int J Mol Sci. 2019;20:4559. https://doi.org/10.3390/ ijms20184559.

32. Weiss R, Schilling E, Grahnert A, Kölling V, Dorow J, Ceglarek U, Sack U, Hauschildt S. Nicotinamide: a vitamin able to shift macrophage differentiation toward macrophages with restricted inflammatory features. Innate Immun. 2015;21:813-26. https://doi.org/10.1177/1753425915602545.

33. Song SB, Park JS, Chung GJ, Lee IH, Hwang ES. Diverse therapeutic efficacies and more diverse mechanisms of nicotinamide. Metabolomics. 2019;15:137. https://doi.org/10.1007/s11306-019-1604-4.

34. Galbraith AR, Seabloom DE, Wuertz BR, Antonides JD, Steele VE, Wattenberg LW, Ondrey FG. Chemoprevention of lung carcinogenesis by dietary nicotinamide and inhaled budesonide. Cancer Prev Res. 2019;12:69-78. https://doi.org/10.1158/1940-6207.CAPR-17-0402

35. D'Arcangelo D, Scatozza F, Giampietri C, Marchetti P, Facchiano F, Facchiano A. Ion channel expression in human melanoma samples: in silico identification and experimental validation of molecular targets. Cancers. 2019:11:446. https://doi.org/10.3390/cancers11040446.

36. Cordella M, Tabolacci C, Senatore C, Rossi S, Mueller S, Lintas C, Eramo A, D’Arcangelo D, Valitutti S, Facchiano A, et al. Theophylline induces differentiation and modulates cytoskeleton dynamics and cytokines secretion in human melanoma-initiating cells. Life Sci. 2019;230:121-31. https://doi.org/10.1016/j.lfs.2019.05.050.

37. Rossi S, Cordella M, Tabolacci C, Nassa G, D'Arcangelo D, Senatore C, Pagnotto P, Magliozzi R, Salvati A, Weisz A, et al. TNF-alpha and metalloproteases as key players in melanoma cells aggressiveness. J Exp Clin Cancer Res. 2018;37:326. https://doi.org/10.1186/s13046-018-0982-1.

38. D'Arcangelo D, Facchiano F, Nassa G, Stancato A, Antonini A, Rossi S, Senatore C, Cordella M, Tabolacci C, Salvati A, et al. PDGFR-alpha inhibits melanoma growth via CXCL10/IP-10: a multi-omics approach. Oncotarget. 2016. https://doi.org/10.18632/oncotarget.12629

39. Tabolacci C, Cordella M, Turcano L, Rossi S, Lentini A, Mariotti S, Nisini R, Sette G, Eramo A, Piredda L, et al. Aloe-emodin exerts a potent anticancer and immunomodulatory activity on BRAF-mutated human melanoma cells. Eur J Pharmacol. 2015;762:283-92. https://doi.org/10.1016/j.ejphar.2015.05. 057.

40. Pfister TD, Reinhold WC, Agama K, Gupta S, Khin SA, Kinders RJ, Parchment RE, Tomaszewski JE, Doroshow JH, Pommier Y. Topoisomerase I levels in the $\mathrm{NCl}-60$ cancer cell line panel determined by validated ELISA and microarray analysis and correlation with indenoisoquinoline sensitivity. Mol Cancer Ther. 2009;8(7):1878-84. https://doi.org/10.1158/1535-7163.MCT-09-0016 Available at https://www.ncbi.nlm.nih.gov/sites/GDSbrowser?acc=GDS1761.

41. Park SJ, Yoon BH, Kim SK, Kim SY. GENT2: an updated gene expression database for normal and tumor tissues. BMC Med Genet. 2019;12(Suppl 5): 101. https://doi.org/10.1186/s12920-019-0514-7.

42. Expression atlas. https://www.ebi.ac.uk/gxa/home. Accessed 10 May 2020.

43. Tang Z, Kang B, Chenwei Li C, Chen T, Zhang Z. GEPIA2: an enhanced web server for large-scale expression profiling and interactive analysis. Nucleic Acids Res. 2019;47(W1):W556-60. https://doi.org/10.1093/nar/gkz430.

44. GEO datasets. https://www.ncbi.n/m.nih.gov/gds. Accessed 20 Feb 2020

45. Talantov D, Mazumder A, Yu JX, Briggs T, Jiang Y, Backus J, et al. Novel genes associated with malignant melanoma but not benign melanocytic lesions. Clin Cancer Res. 2005;11(20):7234-42. https://doi.org/10.1158/10780432.CCR-05-0683.

46. Xu L, Shen SS, Hoshida Y, Subramanian A, Ross K, Brunette JP, et al. Gene expression changes in an animal melanoma model correlate with aggressiveness of human melanoma metastases. Mol Cancer Res. 2008;6(5): 760-9. https://doi.org/10.1158/1541-7786.MCR-07-0344.

47. Gensler HL, Williams T, Huang AC, Jacobson EL. Oral niacin prevents photocarcinogenesis and photoimmunosuppression in mice. Nutr Cancer. 1999;34:36-41. https://doi.org/10.1207/S15327914NC340105.

48. Mould AW, Matthaei Kl, Young IG, Foster PS. Relationship between interleukin-5 and eotaxin in regulating blood and tissue eosinophilia in mice. J Clin Invest. 1997;99:1064-71. https://doi.org/10.1172/JCl119234.

49. Malissen N, Grob JJ. Metastatic melanoma: recent therapeutic progress and future perspectives. Drugs. 2018;78:1197-209. https://doi.org/10.1007/ s40265-018-0945-z.

50. Hwang ES, Song SB. Possible adverse effects of high-dose nicotinamide: mechanisms and safety assessment. Biomolecules. 2020;10(5):687. https:// doi.org/10.3390/biom10050687. 
51. Sen U, Shenoy PS, Bose B. Opposing effects of low versus high concentrations of water soluble vitamins/dietary ingredients vitamin C and niacin on colon cancer stem cells (CSCs). Cell Biol Int. 2017;41:1127-45. https://doi.org/10.1002/cbin.10830.

52. Upadhyay A, Pisupati A, Jegla T, Crook M, Mickolajczyk KJ, Shorey M, Rohan LE, Billings KA, Rolls MM, Hancock WO, et al. Nicotinamide is an endogenous agonist for a C. elegans TRPV OSM-9 and OCR-4 channel. Nat Commun. 2016;7:13135. https://doi.org/10.1038/ncomms13135.

53. Gehring W. Nicotinic acid/niacinamide and the skin. J Cosmet Dermatol. 2004;3:88-93. https://doi.org/10.1111/j.1473-2130.2004.00115.x.

54. Zhang Y, Wu H, Zhang M, Jiang Y, Zhuo W, Zhang Y, Hua S. Nicotinamide induces apoptosis of F9 mouse teratocarcinoma stem cells by downregulation of SATB1 expression. Tumor Biol. 2015;36:4339-48. https:/ doi.org/10.1007/s13277-015-3073-3.

55. Li S, Li X, Guo H, Liu S, Huang H, Liu N, Yang C, Tang P, Liu J. Intracellular ATP concentration contributes to the cytotoxic and cytoprotective effects of adenosine. PLoS One. 2013;8:e76731. https://doi.org/10.1371/journal.pone. 0076731.

56. Valko M, Rhodes CJ, Moncol J, Izakovic M, Mazur M. Free radicals, metals and antioxidants in oxidative stress-induced cancer. Chem Biol Interact. 2006;160:1-40. https://doi.org/10.1016/j.cbi.2005.12.009.

57. Li K, Zhao S, Long J, Su J, Wu L, Tao J, Zhou J, Zhang J, Chen X, Peng C. A novel chalcone derivative has antitumor activity in melanoma by inducing DNA damage through the upregulation of ROS products. Cancer Cell Int. 2020;20:36. https://doi.org/10.1186/s12935-020-1114-5.

58. Han X, Han Y, Zheng Y, Sun Q, Ma T, Zhang J, Xu L. Chaetocin induces apoptosis in human melanoma cells through the generation of reactive oxygen species and the intrinsic mitochondrial pathway, and exerts its antitumor activity in vivo. PLoS One. 2017;12:e0175950. https://doi.org/10.1371/ journal.pone.0175950.

59. Li Z, Huang L, Wei L, Hou Z, Ye W, Huang S. Chaetocin induces caspasedependent apoptosis in ovarian cancer cells via the generation of reactive oxygen species. Oncol Lett. 2019. https://doi.org/10.3892/ol.2019.10507.

60. McGlynn LM, Zino S, MacDonald Al, Curle J, Reilly JE, Mohammed ZM, McMillan DC, Mallon E, Payne AP, Edwards J, Shiels PG. SIRT2: tumour suppressor or tumour promoter in operable breast cancer? Eur I Cancer 2014;50:290-301. https://doi.org/10.1016/j.ejca.2013.10.005.

61. Kim HS, Vassilopoulos A, Wang RH, Lahusen T, Xiao Z, Xu X, Li C, Veenstra TD, Li B, Yu H, Ji J, Wang XW, Park SH, Cha YI, Gius D, Chu-Xia Deng CX. SIRT2 maintains genome integrity and suppresses tumorigenesis through regulating APC/C activity. Cancer Cell. 2011;20(4):487-99. https://doi.org/10 1016/j.ccr.2011.09.004.

62. Hiratsuka M, Inoue T, Toda T, Kimura N, Shirayoshi Y, Kamitani H, et al. Proteomics-based identification of differentially expressed genes in human gliomas: down-regulation of SIRT2 gene. Biochem Biophys Res Commun. 2003;309:558-66. https://doi.org/10.1016/j.bbrc.2003.08.029.

63. Lai CC, Lin PM, Lin SF, Hsu CH, Lin HC, Hu ML, Hsu CM, Yang MY. Altered expression of SIRT gene family in head and neck squamous cell carcinoma. Tumour Biol. 2013;34(3):1847-54. https://doi.org/10.1007/s13277-013-0726-y.

64. Zhang LL, Zhan L, Jin YD, Min ZL, Wei C, Wang Q, Chen YJ, Wu QM, Hu XM, Yuan Q. SIRT2 mediated antitumor effects of shikonin on metastatic colorectal cancer. Eur J Pharmacol. 2017;797:1-8. https://doi.org/10.1016/j. ejphar.2017.01.008.

65. Audrito V, Managò A, Gaudino F, Deaglio S. Targeting metabolic reprogramming in metastatic melanoma: The key role of nicotinamide phosphoribosyltransferase (NAMPT). Semin Cell Dev Biol. 2020;98:192-201. https://doi.org/10.1016/..semcdb.2019.05.001

66. Wilking-Busch MJ, Ndiaye MA, Liu X, Nihal Ahmad N. RNA interferencemediated knockdown of SIRT1 and/or SIRT2 in melanoma: identification of downstream targets by large-scale proteomics analysis. J Proteome. 2018; 170:99-109. https://doi.org/10.1016/j.jprot.2017.09.002.

67. Carafa V, Altucci L, Nebbioso A. Dual tumor suppressor and tumor promoter action of sirtuins in determining malignant phenotype. Front Pharmacol. 2019;10:38. https://doi.org/10.3389/fphar.2019.00038.

68. Karwaciak I, Gorzkiewicz M, Ryba K, Dastych J, Pulaski L, Ratajewski M. AC93253 triggers the downregulation of melanoma progression markers and the inhibition of melanoma cell proliferation. Chem Biol Interact. 2015;236: 9-18. https://doi.org/10.1016/j.cbi.2015.04.016.

69. Karwaciak I, Sałkowska A, Karaś K, Sobalska-Kwapis M, Walczak-Drzewiecka A, Pułaski L, Strapagiel D, Dastych J, Ratajewski M. SIRT2 contributes to the resistance of melanoma cells to the multikinase inhibitor dasatinib. Cancers. 2019;11(5):673. https://doi.org/10.3390/cancers11050673.

70. Rumpf T, Schiedel M, Karaman B, Roessler C, North BJ, Lehotzky A, Oláh J, Ladwein KI, Schmidtkunz K, Gajer M, et al. Selective Sirt2 inhibition by ligand-induced rearrangement of the active site. Nat Commun. 2015;6:6263. https://doi.org/10.1038/ncomms7263.

71. Wang Y, Fung YME, Zhang W, He B, Chung MWH, Jin J, Hu J, Lin H, Hao Q. Deacylation mechanism by SIRT2 revealed in the 1'-SH-2'-O-Myristoyl intermediate structure. Cell Chem Biol. 2017;24:339-45. https://doi.org/10. 1016/j.chembiol.2017.02.007.

72. Jang S, Kang HT, Hwang ES. Nicotinamide-induced mitophagy. J Biol Chem. 2012;287:19304-14. https://doi.org/10.1074/jbc.M112.363747.

73. Sun F, Jiang X, Wang X, Bao Y, Feng G, Liu H, Kou X, Zhu Q, Jiang L, Yang Y. Vincristine ablation of Sirt2 induces cell apoptosis and mitophagy via Hsp70 acetylation in MDA-MB-231 cells. Biochem Pharmacol. 2019;162:142-53. https://doi.org/10.1016/j.bcp.2018.10.021.

74. Surjana D, Halliday GM, Damian DL. Role of Nicotinamide in DNA damage, mutagenesis, and DNA repair. J Nucleic Acids. 2010;2010:1-13. https://doi. org/10.4061/2010/157591.

75. Nair $\mathrm{AB}$, Jacob $\mathrm{S}$. A simple practice guide for dose conversion between animals and human. J Basic Clin Pharm. 2016;7:27-31. https://doi.org/10. 4103/0976-0105.177703.

76. Knip M, Douek IF, Moore WPT, Gillmor HA, McLean AEM, Bingley PJ, Gale EAM. Safety of high-dose nicotinamide: a review. Diabetologia. 2000;43: 1337-45. https://doi.org/10.1007/s001250051536.

77. Horsman MR, Hoyer M, Honess DJ, Dennis IF, Overgaard J. Nicotinamide pharmacokinetics in humans and mice: a comparative assessment and the implications for radiotherapy. Radiother Oncol. 1993;27:131-9. https://doi. org/10.1016/0167-8140(93)90133-S.

78. Winter $\mathrm{H}$, Hu HM, McClain K, Urba WJ, Fox BA. Immunotherapy of melanoma: a dichotomy in the requirement for IFN- $\gamma$ in vaccine-induced antitumor immunity versus adoptive immunotherapy. J Immunol. 2001;166: 7370-80. https://doi.org/10.4049/jimmunol.166.12.7370

79. Mattes J, Hulett M, Xie W, Hogan S, Rothenberg ME, Foster P, Parish C. Immunotherapy of cytotoxic T cell-resistant tumors by T helper 2 cells. J Exp Med. 2003;197:387-93. https://doi.org/10.1084/jem.20021683.

80. Ellyard Jl, Simson L, Parish CR. Th2-mediated anti-tumour immunity: friend or foe? Tissue Antigens. 2007;70:1-11. https://doi.org/10.1111/j.1399-0039. 2007.00869.x.

81. Lorvik KB, Hammarström C, Fauskanger M, Haabeth OAW, Zangani M, Haraldsen G, Bogen B, Corthay A. Adoptive transfer of tumor-specific Th2 cells eradicates tumors by triggering an in situ inflammatory immune response. Cancer Res. 2016;76:6864-76. https://doi.org/10.1158/0008-5472. CAN-16-1219.

82. Moreira A, Leisgang W, Schuler G, Heinzerling L. Eosinophilic count as a biomarker for prognosis of melanoma patients and its importance in the response to immunotherapy. Immunotherapy. 2017;9:115-21. https://doi. org/10.2217/imt-2016-0138.

83. Aldinucci D, Colombatti A. The inflammatory chemokine CCL5 and Cancer progression. Mediat Inflamm. 2014;2014:1-12. https://doi.org/10.1155/2014/ 292376.

84. Payne AS, Cornelius LA. The role of chemokines in melanoma tumor growth and metastasis. J Invest Dermatol. 2002;118:915-22. https://doi.org/ 10.1046/j.1523-1747.2002.01725.x.

85. Wiguna AP, Walden P. Role of IL-10 and TGF- $\beta$ in melanoma. Exp Dermatol. 2015;24:209-14. https://doi.org/10.1111/exd.12629.

86. Dentelli P, Rosso A, Olgasi C, Camussi G, Brizzi MF. IL-3 is a novel target to interfere with tumor vasculature. Oncogene. 2011;30:4930-40. https://doi. org/10.1038/onc.2011.204.

87. Petrack B, Greengard P, Craston A, Sheppy F. J Biol Chem. 1965;240:1725-30

88. Manrika I, Petrovska R, Klovins J. Evidence for constitutive dimerization of niacin receptor subtypes. Biochem Biophys Res Commun. 2010;395:281-7. https://doi.org/10.1016/j.bbrc.2010.04.011.

\section{Publisher's Note}

Springer Nature remains neutral with regard to jurisdictional claims in published maps and institutional affiliations. 